\title{
The impact of minimum wages on youth employment in Portugal
}

\author{
Sonia Cecilia Pereira
}

Research Memorandum 0004

OCFEB

Research Centre for Economic Policy

P.O. Box 1738

3000 DR Rotterdam

The Netherlands

e-mail: ae-OCFEB-secr@ few.eur.nl

telephone +31 10408 2430/2446

telefax +31104089173 


\title{
The impact of minimum wages on youth employment in Portugal
}

\author{
Sonia Cecilia Pereira*
}

\begin{abstract}
From January 1, 1987, the legal minimum wage for workers aged 18 and 19 in Portugal was uprated to the full adult rate, generating a 49.3\% increase between 1986 and 1987 in the legal minimum wage for this age group. This shock is used as a "natural experiment" to evaluate the impact of the minimum wage change on teenagers' employment by using a large firm level micro-data set. It is shown that by comparing the employment growth of 18-19 year old workers with their 20-25 year old counterparts one can identify the employment effects of the minimum wage hike. The same comparisons are done with 30-35 year old workers. This study finds that the rise in the minimum wage significantly reduced employment. This conclusion is reinforced by evidence showing that these employment effects are concentrated in firms more likely to be affected by the change in the law.
\end{abstract}

* Economics Department, University College London, Gower St, WC1 London.

$1 \quad$ I am very grateful to Stephen Machin and Jonathan Thomas for their encouragement and stimulating guidance. I am also grateful to seminar participants at the University College London, Sociedade Portuguesa de Investigadores em Economia 1998 Conference, European Society of Population Economics 1999 conference, European Economic Association 1999 conference, and International Institute of Public Finance 1999 conference. Thanks are also due to the Statistics Department of the Ministry of Qualification and Employment and in particular to Luís Silva for excellent work in data collection, to Eduarda Ribeiro and Miguel Gouveia for fruitful discussions, and to PRAXIS XXI Programme for financial support.

I would like to express my deep gratitude to Idalina, Fernando, Luís, Maria, Fernanda and Alfredo for their unconditional support.

Corresponding author, Email: s.pereira@ucl.ac.uk

JEL classification: J23; J30.

Keywords: Minimum wages; Youth employment; Natural Experiment 


\section{Table of Contents}

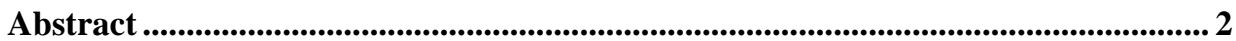

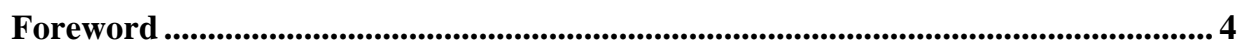

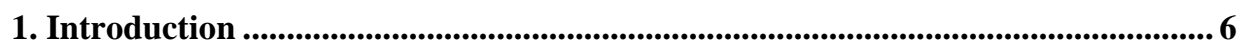

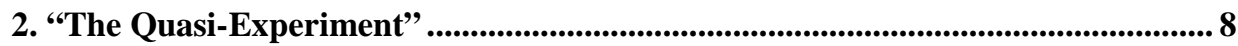

3. The data ........................................................................................................................... 11

4. Minimum wages and wage changes .............................................................................. 12

5. Difference in differences: estimates of employment effects..................................... 19

6. Difference in differences: second experimental design................................................. 25

7. Firms' entries and exits.................................................................................................. 28

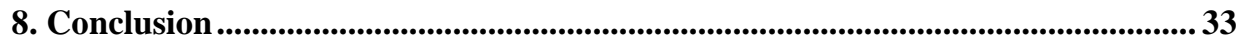

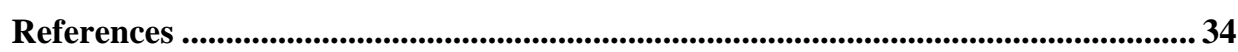

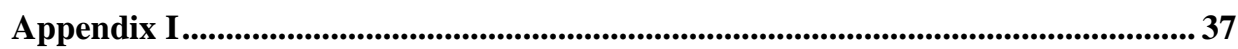

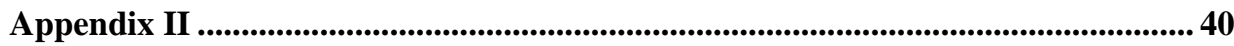

Appendix III.......................................................................................................................... 42 


\section{Foreword}

One of the most challenging and at the same time still controversial topics in labor economics is the effect of the minimum wage on labor market outcomes. This research memorandum was presented at a workshop organized by OCFEB and the Tinbergen Institute in April 2000. The focus was on recent developments in the analysis of the minimum wage. A mix of theory and empirical papers were presented at this workshop. The theory papers show that frictionless Walrasian models are not able to explain the stylized facts. Instead, we need modern economic theories which deal with imperfect information and other market imperfections to derive novel insights into these effects. The empirical papers show how a careful empirical analysis can shed new lights on the magnitudes of the effects. Below we give a short overview of all the papers that were presented at the workshop.

The Research Memorandum 0004 by Sonia Pereira (University College London), "The impact of minimum wages on youth employment in Portugal", is about a natural experiment in Portugal. From January 1, 1987, the legal minimum wage for workers aged 18 and 19 in Portugal was raised to the full adult rate, generating a $49.3 \%$ increase between 1986 and 1987 in the legal minimum wage for this age group. This shock is used to evaluate the impact of the minimum wage change on teenagers' employment. Her conclusion is that the rise in the minimum wage significantly reduced employment.

The Research Memorandum 0005 of Chris Flinn (New York University), "Interpreting minimum wage effects on wage distributions: a cautionary tale", argues that welfare effects of minimum wage effects can only be drawn by using empirical evidence on employment changes, the wage distribution and a formal model in which welfare can be defined in a meaningful and rigorous way. Flinn shows that negative employment effects by itself do not tell us much about the aggregate welfare effects of the minimum wage.

The Research Memorandum 0006 of Francis Kramarz and Thomas Philippon (University of Paris I, CREST, and MIT respectively), "The impact of differential payroll tax subsidies on minimum wage employment", uses changes in compensation costs and minimum wages, to get observations of up- and down- variation in real minimum wages. They get up-and down-movements in minimum wages in the US, with differentiation by state, and in France an equivalent-minimum is defined, which normalizes on the compensation cost in a base year and looks at variations in the underlying minimum and payroll taxes to get up- and down-variation in the equivalent minimum in France. They find no significant effects in the United States but strong and significant effects in France.

In the Research Memorandum 0007 by Pieter Gautier and Coen Teulings (Erasmus University Rotterdam, Tinbergen Institute, OCFEB), "A large piece of a small pie: minimum wages and unemployment benefits in an assignment model with search 
frictions", an assignment model with search frictions is offered that is consistent with the following stylized facts: a spike at the minimum wage, compression of wage differentials at a large interval above the minimum wage and small employment losses. The introduction of a minimum wage in their model makes some matches at the lower segments no longer profitable. In addition it leads to a redistribution of rents from firms to low skilled workers. A minimum wage fulfills a potential useful role in this model in the sense that it prevents low skilled workers from accepting jobs for which they are ill suited.

Finally, Research Memorandum 0002 by Gerard van den Berg (Free University Amsterdam, Tinbergen Institute, CEPR, OCFEB), "Multiple equilibria and minimum wages in labor markets with informational frictions and heterogeneous production technologies", discusses an equilibrium search model in which imposition of a minimum wage affects wages even though, after imposition, the lowest wage in the market is strictly larger than the minimum wage and there is no spike, so that it seems that the minimum wage is irrelevant. The minimum wage effects are a consequence of the fact that the model has multiple equilibria. This, in turn, is because the reservation wage of the unemployed and the lowest production technology in use affect each other. He shows that multiplicity is an empirically relevant phenomenon, using data from Denmark and the United States. A minimum wage policy can be fruitfully applied to single out the desirable equilibrium.

Gerard J. van den Berg

Pieter A. Gautier 


\section{Introduction}

This paper evaluates the employment impact of the abolishment of minimum wage reductions for teenagers that took place in Portugal on the $1^{\text {st }}$ of January 1987. With this minimum wage policy, workers aged 18 and 19 became entitled the full adult rate, instead of the previous 75\%. This represented a 49.3\% increase between 1986 and 1987 in the legal minimum wage for this age group. This large change in the minimum wage of a particular group of workers offers very good conditions for a "natural experiment" in which employment variations of 18 and 19 year olds (treatment group) can be compared with those of older workers (control groups).

This methodology is not new in evaluating the impact of minimum wages (MW) on employment. Early studies on MW by Richard Lester (1946) and others used "natural experiments" to study the effect of the introduction of the federal minimum wage in the US. This approach has been revived by Card (1992a), Card and Krueger (1994) using MW cross state variations in the US and by Card (1992b), Katz and Krueger (1992) and Schmitt and Bernstein (1997) to look at the effect of changes in the US federal law.

Given the nature of the problem, the "natural experiment" approach has a clear advantage over other most common methodologies: it makes use of a large exogenous variation in the minimum wage. In fact, very often, MW do not vary much over time or across regions or groups of workers. Adding to the fact that both in time-series and cross-section studies the measures of MW variation mostly used are the ratio of MW over average wage and the Kaitz index (H. Kaitz, 1970), these studies face the problem of using a variable of interest exhibiting relatively little variation and in which most of that variation may not come from the minimum wage itself. Moreover, the minimum wage variation may be endogenous, as it depends on political decisions and the timing and extent of any change may be correlated with employment expectations. This has the potential to seriously bias employment effect estimates.

The problem of the impact of minimum wages on employment is of particular importance given the intense debate that is taking place both on the empirical and on the theoretical grounds. In fact, the existing evidence fails to give a clear-cut answer about the employment effects of minimum wage policies. In Brown, Gilroy and Kohen' survey (1982) they concluded (mainly based on time-series studies using US data before the 1980s) that a $10 \%$ increase in the minimum wage reduces teenage employment by 1 to $3 \%$, though with no identifiable effect on the adult labour market. This apparent consensus has been challenged by subsequent research well represented in Card and Krueger (1995). By using different datasets and methodologies as well as reinterpreting and re-examining previous studies they concluded that "the new evidence points towards a positive effect of the minimum wage on employment; most shows no effect at all" (page1). 
However, their work has been strongly criticised (see the reviews of Card and Krueger in the Industrial and Labor Relations Review, 1995; papers on the minimum wage in the American Economic Review, 1995; Neumark and Washer, 1995; Schmitt and Bernstein, 1997) and has been followed by a resurgence of work on this topic.

The most recent studies using new datasets and methodologies have failed to reconcile the existing conflicting results. The OECD Employment Outlook for 1998 has an assessment of the literature on this topic and states: "while differences in methodology may account for some of the widely differing results which have emerged, it is more difficult to reconcile the contradictory results which have arisen even when similar data and estimation techniques have been used" (page 45).

There are nevertheless two hypotheses that seem to be supported by existing evidence. First, if there is in fact a negative employment effect this is stronger among youths (Brown et al., 1982, Dolado et al., 1996, Abowd et al., 1997, OECD Employment Outlook, 1998). Second, employment effects of minimum wage changes may depend strongly on the particular context in which they are implemented, namely the ratio of minimum wage to average wages, the share of workers paid at the minimum, the point in the economic cycle.

This is why it is of particular interest to evaluate the employment impact of the big minimum wage shock that took place in Portugal in the mid 80s that was aimed directly at teenagers: if it exists anywhere, this is the kind of situation where one can expect to observe a rather strong employment effect. In the period from 1984 to 1986 the average ratio of minimum wages to average wages in Portugal was still 56\%. In the US this ratio was already below $50 \%$ during the 70 's, and went well below $40 \%$ during the 80 s. (Source: OECD, Minimum Wage database). Moreover, the share of workers under 20 paid close to the minimum in that period is considerably high (see section 4 below). A third reason for a potentially strong negative employment impact is the fact that Portugal is a small open economy with little possibility of adjusting to such a shock via product price increases. In fact, not only Portugal was already part of the European Union but also the secondary sector had still strong importance when compared to the services sector. It is well known that in general only services have any chance of insulating from international competition.

The existence of an administrative dataset covering the universe of the Portuguese firms makes it possible to use a highly representative sample of firms for Portugal. Also, the results will prove robust to using different identification assumptions and specifications. Namely the crucial hypothesis that the employment of the different age groups would evolve similarly if there has not been the MW change will be tested.

This study concludes that in Portugal the impact of eliminating MW reductions for teenagers was rather harmful for teenagers' employment. The estimated elasticity is between -0.2 and -0.4 for teenagers. From what has been said, these values are 
unsurprisingly at the top of the range (in absolute terms) of values usually found in the literature. Moreover, what is at stake is the impact of an extremely large change in the MW (35.5\% in real terms) $)^{2}$. There is also evidence of some substitution towards older workers, ie, young adults' employment seems to have risen slightly with this MW policy.

The structure of this paper is as follows: the next section summarises the institutional aspects of minimum wages in Portugal, namely the conditions under which the change in the law took place. Section 3 describes the dataset used. Section 4 inspects the wage distributions of the various age groups of workers before and after the MW change. Section 5 presents the difference in differences analysis which is extended by using firms as control groups in section 6 and by including firm entrants and exitors in section 7. Section 8 concludes.

\section{2. "The Quasi-Experiment"}

Statutory minimum wages were introduced in Portugal in 1974 following the democratic revolution in the same year. Nowadays called RMMG (Remuneração Mínima Mensal Garantida), MW have undergone several transformations over the years ${ }^{3}$. This study uses a particular change that took place in January of 1987. Up to that date, the total amount of RMMG was due to workers at least 20 years old. Workers aged 18 and 19 years old were entitled 75\% of RMMG. From then onwards, the latter were entitled the complete $\mathrm{RMMG}^{4}$.

Changes in RMMG levels were then expected to occur every January, as since 1983 this had been the common practice ${ }^{5}$. They would be published in the press, as soon as they

2 Given the particular setting of this study, its results are not too dissimilar from the existing literature for Portugal. Ribeiro (1993) and Pimentel (1995) regressed employment to population ratios against several MW measures and found elasticities close to zero for adults and elasticities around -0.1 for male teenagers and male young adults. Female teenagers and female young adults seemed to have much higher elasticities of -0.2 and -0.47 .

3 A detailed description of the Portuguese minimum wage institutional setting and historical evolution is given in the appendix I.

4 Some exceptions were allowed: for handicapped workers reductions for up to $50 \%$, for apprentices 20\% reductions for no more than two years and only in exceptional circumstances. Finally, firms with less than 5 workers could pay the agricultural RMMG (88\% of the nonagricultural RMMG in 1987). This was already possible since the late 70's, although the bureaucratic process was made simpler in 1987. Still, these small firms were now required to pay the full agricultural minimum wages to workers aged 18 or more and not 20 or more as before.

5 The minimum wage levels were revised on a year basis to take into account the evolution of inflation and average wages. 
were approved by the parliament in December. In particular, the new law in which we are focusing was publicly discussed during December of 1986, and was announced in the daily papers on the last day of that year, to be applicable from the first of January 1987.

This study will look at the short and medium term impact of this change. In order to do that, it uses a five year panel of firms since 1985 to 1989 . The information in each wave refers to the month of March. Being so, 1986 corresponds to the situation 9 months before the change and 1987 refers to 3 months later. However, by using data from 1985, 1988 and 1989 it will possible to evaluate the immediate as well as the medium term impacts. 1985 and 1986 waves will be considered as qualified to represent the state of art before the experiment, while the remaining years will be considered as having occurred after the change in the RMMG. The time elapsed between March 1986 and the change in the law is long enough to ensure that no anticipated adjustments were made. In fact, August 1986 is the first time that there was any news in the Portuguese papers about a claim to change the starting age for being entitled the full RMMG.

The analysis will be mostly centred on the periods 1986 and 1988. Using these two years corresponds to using information of 9 months before the change and 15 months after the change. From the several alternative combinations of years, this is by far the one considered the most adequate. 1987 allows for only 3 months of adjustment, and it is well known that replacing the workforce has adjustment costs of hiring and firing that translate into time lags. By using 1989 one uses as means of comparison the employment situation 27 months after the change in the law. It is perhaps too naive to believe that the ceteris paribus condition that will be required for this study will hold for such a long period.

Turning now to the methodology used in this work, the basic idea underlying a "Natural experiment" is the same as the one of the experimental method, at the core of natural sciences' empirical research. The latter consists of randomising a representative sample of "individuals" in two groups, the treatment group and the control group, maintaining both groups under similar conditions except that one receives the treatment and the other does not. The impact of the treatment is given by the difference between the two groups' outcomes.

As long as the samples are large, the fact that the two groups were randomly generated gives no reason to believe that in the absence of the experiment the treatment group should behave differently from the control group. Put another way the control group provides the counterfactual for what would have happened to the treatment group, had it not received the treatment.

"Natural experiments" like the method just described, examine the measured outcome of a relevant variable in treatment groups and comparison groups. However, these groups are not randomly assigned. Instead, they are in most cases the result of policy 
changes (they can also be generated by government randomisation). As opposed to an ideal experiment, one cannot control for the changes one is using as a source of variation. They can however create conditions for a "natural experiment" as long as they generate transparent exogenous variation in the explanatory variables that determine the treatment assignment" (Meyer, 1995).

In practice, a first requirement for a "natural experiment" is the occurrence of an exogenous shock that should be at once unanticipated and large. As has already been said, the shock we are concerned with was clearly unanticipated. It was also an exogenous shock. The logic behind the new law had to do with legal rights and citizenship and not with employment concerns. In the past, for legal matters an individual was considered an adult at 21 . During the eighties it had been already established that 18 years old was the age at which an individual was entitled to full rights and duties in the legal system. This law generalised this principle to the statutory minimum wage. One could argue that the timing of the decision may have been related with the positive trends in the economy and in particular in the labour market during the period. In any case, that will be taken into account for external validity considerations ${ }^{6}$.

Finally, the minimum wage change was remarkably large. Between December 1986 and January 1987, the younger workers saw their MW increased by $49.3 \%$, while workers aged 20 or more experienced an increase in their MW of only $12 \%$. The corresponding percent increases in real terms are $35.5 \%$ for the former group and $1.6 \%$ for the latter one.

In this case the "quasi experiment" evaluates the employment impact on workers aged 18 and 19 years old by making use of the unexpected and large variation in the MW for this particular range of young workers. The two control groups consist of two older groups of workers in the same firm, namely those aged 20 to 25 (young adults) and 30 to 35 years old (older adults). The treatment group, i.e., those aged 18 and 19, will be referred to as teenagers in the rest of the paper. Teenagers will experience an exogenous percent increase of the applicable real MW that exceeds the one of the control groups by 33.9 points.

To avoid relying solely on age groups as control groups and as a means to test their adequacy as controls, the analysis will be extended by grouping firms according to their likelihood of being affected by the new law. In particular if there is an employment effect resulting from the MW increase, this should be stronger among firms that were previously taking advantage of the possibility of paying lower wages to their teenagers than in the remaining firms.

6 Meyer (1995) divides the conditions for validity of a "natural experiment" into the ones that ensure internal validity - whether valid inference can be drawn from the particular "natural experiment" - and external validity - to which extent the conclusions can be generalized. 
Given the fact that the available data is aggregated at the age group and firm levels, it is hard to determine precisely which firms were most likely to be affected. Perfect information could only be gathered if one knew how many workers were being paid wages below the adults' minimum and by how much. As there are workers not covered by the MW law, either because their apprenticeship status or because of noncompliance, it was established that firms most likely to suffer an impact from the abolishment of the teenagers MW reduction were those that in 1986 were paying their 18 and 19 year old workers average monthly wages at or above the MW due to this workers, but below the adults' statutory $\mathrm{MW}^{7}$.

In practice the difference between the employment variation of teenagers minus the employment variation of older workers in firms considered more likely to be directly affected by the new minimum will be compared with similar variables in firms less likely to be directly affected by the new legislation.

\section{The data}

The data used in this work was computed from an extensive data source, Quadros de Pessoal (QP), produced by the DEMQE (Statistics Department of the Ministry of Qualification and Employment). All firms established in Portugal (Azores and Madeira Islands are included) with paid workers are legally required to report to this database. Being so, very small firms with only self employed people or family workers are not accounted for. A thorough evaluation of the coverage of QP through the comparison with Census data reveals that QP covers more workers than the Census itself, despite the fact that very small firms are underrepresented ${ }^{8}$.

The data is gathered annually and refers to the situation of firms and workers in March of each year (for the years under analysis). A random sample was drawn to obtain 30 per cent of the Portuguese firms in $1986^{9}$. The panel was then constructed by following these firms from 1985 to 1989.

In order to maintain the representativeness of the sample for the period 1986 to 1988, a random sample was drawn of 30 percent of the firms that started activity in 1987, and these firms were followed until 1988. Similarly, a random sample was drawn of 30 percent of the firms that started activity in 1988. This panel gives track of the firms which died between 1986 and 1987, as they are in the survey in 1986 but are not present

7 For obvious reasons, this criterion is likely to suffer from measurement error of different sources. First because of the average effect mentioned, then because it assumes that workers paid monthly wages in this range work full time and finally also because there is nothing ensuring that these firms will not change the status of their young workers in order not to increase wages, or that they will comply with the law.

8 This comparison has been done by Cardoso, 1997.

$930 \%$ of the population corresponded to 32031 firms in 1986. See Table 1 in annex. 
in the following years. Firms that died between 1987 and 1988 can be identified likewise $^{10}$. This study will also use a random sample of the firms born in 1986 by selecting those that did not exist yet in 1985. Finally, for the analysis with firms' entries and exits, a random sample of $30 \%$ of the firms that died from 1985 to 1986 was also collected.

Firm level data was gathered for three age groups. The treatment group comprises workers aged 18 and 19 years old. The control groups were those aged between twenty and twenty-five and between thirty and thirty-five, all closed intervals. For each of these groups the following variables were collected: the total number of workers with ages in that interval employed by the firm (in the payroll of the firm), average monthly hours and overtime hours worked per individual, same for overtime hours, total wages for normal hours and total wages for overtime. The following set of firm characteristics ${ }^{11}$ was also collected: size, district and industry. Size is the number of workers that have worked or provided any service as self employed for the firm during March of that year. Contrary to the age groups employment variables, which just include those workers in the payroll of the firm, size comprises temporary contracts as well as long-term contracts and self-employed workers providing services to the firm. The regional index at the distrito level divides Inland Portugal in 18 area locations. They were re-ordered into 7 larger regions believed to give a good picture of the economic regional differences across the country ${ }^{12}$. Firms' economic activity classification (CAE 6Digit) was rearranged into 18 broader groups, defined according to National Institute of Statistics (INE) criteria.

For the purpose of the present study firms located in the islands were dropped, as they have regional governments, with autonomous policies. Public administration firms were also excluded, for their employment policies are probably in many respects insulated from market considerations, and I am primarily concerned with what happens to the private economy. Finally, firms belonging to the primary sector or whose economic activity is domestic work were dropped as they have specific minimum wage regimes.

\section{Minimum wages and wage changes}

The occurrence of an exogenous shock that is at once unanticipated and large may not be enough for a valid "experiment". In fact, a policy change may fail to have a real

10 Firms were considered dead if they were not in the survey in the next two following years.

11 For the panel, this information refers to the year of 1986, for entries and exits, refers to the relevant years. Date of creation of the firm was not available in the survey in those years, and other financial and ownership indicators were information not disclosed because of confidentiality concerns.

12 The country is partitioned into Northern Coastal region, Northern Inland region, Central Coastal region, Central Inland region, Lisbon and Tagus Valley, Alentejo and Algarve. 
impact on the restrictions faced by the economic agents. Being so, the first requirement for internal validity of this "quasi-experiment" is that there is actually a treatment group, i.e., the impact of the change in the minimum wage of workers aged 18 and 19 on their wage distribution is much heavier than the one of the new MW value for older workers.

The wage distributions of the various groups of workers confirm that this is indeed the case. Figure 1 depicts the wage distributions for the 3 age groups in 1986 and $1987^{13}$. For the workers aged 18 and 19 (figure 1a) there are two spikes in 1986: one at the interval 16-18 and the other one at the interval 22-24 thousand escudos. The former corresponds to the minimum wage enforced by law with respect to this age level employees (16875 escudos) ${ }^{14}$. The latter corresponds to the general compulsory minimum wage for non-agricultural workers aged 20 or older (22500 escudos). The second spike is larger than the first: $15 \%$ of the workers lie in the 16-18 interval, while $20 \%$ lie in the 22-24 interval. This indicates that the particular minimum wage for 18-19 year old workers imposes a binding restriction on their wage distribution, although part of these workers are already paid at least the full MW.

13 These wage distributions have some inprecisions introduced by the inclusion of part time workers. As what is depicted is the monthly wage, the relationship between these workers' wages and the minimum wage is lost. Not all workers with wages below the 1819 year old minimum need to be part timers, however. There are partial minimum wage exemptions for handicapped, apprentices and very small firms.

14 This value is obtained by: $22500 \mathrm{x} 0.75$. 
Fig. 1 (a-c). Wage distributions in 1986 and 1987. (a) 18-19 year old workers; (b) 20-25 year old workers; (c) 30-35 year old workers.

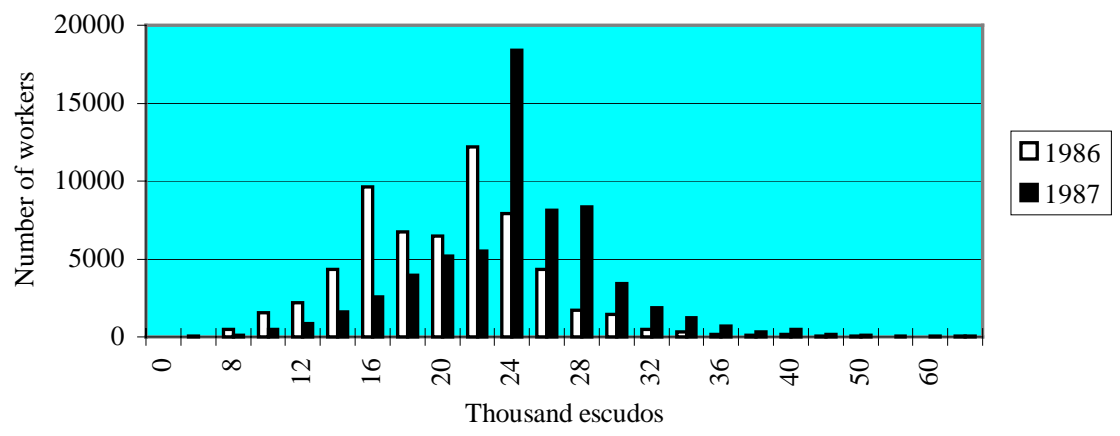

(a)

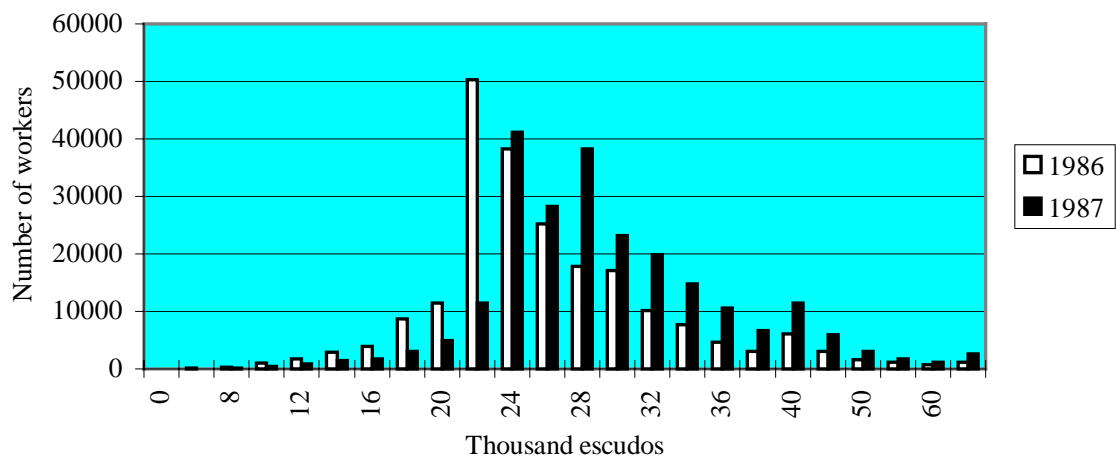

(b)

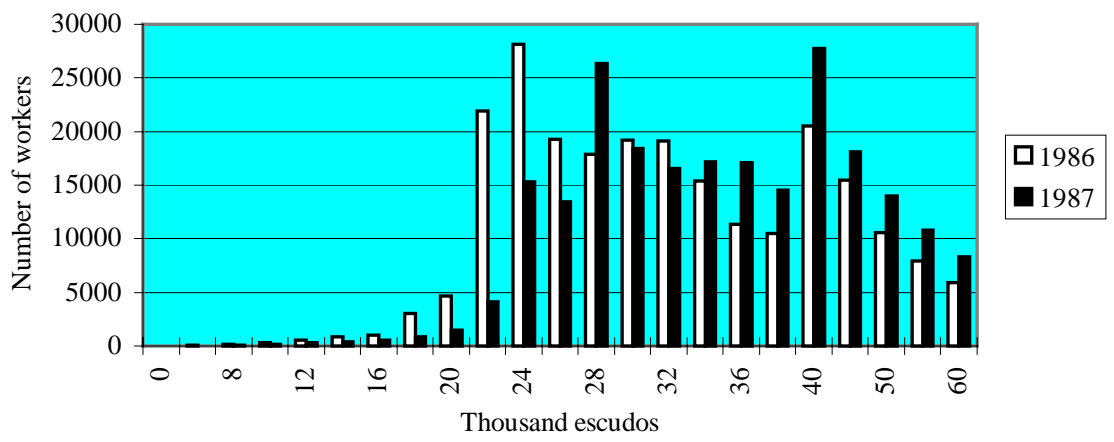

(c) 
In 1987 however, a very sharp spike can be observed at the 24-26 interval, which encloses the new minimum (25200). Twenty nine percent of the workers will receive wages within this interval ${ }^{15}$. It is worth noting that for workers receiving 16875 escudos in 1986 and the new minimum in 1987 (25200 escudos) the jump in the minimum wage is huge $(49.3 \%)$. These $49.3 \%$ correspond to a $35.5 \%$ increase in real terms.

Looking at the wage distributions for the 20-25 years old workers (figure 1b) it is clear that the compulsory minimum wage cuts the wage distribution in 1986, so that there are no doubts that it is imposing a binding restriction on these workers' wages. In 1987 however, the renewed statutory minimum seems to have lost most of its bite. In fact, while in $1986,23 \%$ of 20 to 25 year old workers had wages in the 22-24 interval, in 1987 only $17 \%$ had wages between 24 and 26 thousand escudos. The wage distribution seems to have moved up independently of the minimum wage change. Note that the change in the value of the statutory minimum for these workers corresponded to no more than $1.6 \%$ increase in real wages.

Figure 1c displays the evolution of 30-35 year old workers wage distributions. Again, the statutory minimum wage seems to have been more restrictive in 1986 than in 1987. The wage distribution was sharply cut at the 22-24 interval in 1986, although many workers were already receiving wages in the interval immediately after. In 1987, the number of workers at the statutory minimum interval falls quite dramatically, and one can observe a fairly even distribution with peaks at round numbers (30 and 40 thousand escudos).

From a simple observation of the relevant age groups' wage distributions, it is possible to conclude that the shock in the statutory minimum applied to those aged 18 and 19 years has had a clear impact on the wage distributions of these workers. Moreover the new value of the minimum wage for adults failed to maintain its importance in terms of representing an active restriction on low wages. In fact, the new minimum hardly compensated for price increases and fell behind average wages.

The same conclusion is drawn if one uses the wage data available in the sample. The average proportional wage change of each of the 3 age groups of workers is compared with the one of the remaining groups. The formulation used is similar to the one of difference in differences regressions, carefully explained ahead, in section 5. Basically, the proportional wage variation between the year before the change and the year after the change in the MW is computed for each age group. This measure is then compared for every combination of two age groups, so that one can check whether the average wage of the treatment group (those aged 18 and 19) has had a sizeable proportional increase relatively to the control groups. The relative wage changes between the two control groups will also be compared.

1520000 out of 63578 workers are at the interval close the minimum wage. Note that 25200 is not in the beginning of the interval, as it was with the previous values 
The equation estimated is the following:

$$
\Delta W_{i j t}=\alpha+\beta d_{i}+\not X_{i j t}+\varepsilon_{i j t}
$$

where $\Delta \mathrm{W}_{\mathrm{ijt}}=\left(\left.W_{i j t}\right|_{t=1}-\left.W_{i j t}\right|_{t=0}\right) /\left.W_{i j t}\right|_{t=0}$, is the proportional change in the hourly real wage

of workers of age group $\mathrm{i}$ in firm $\mathrm{j}$ between time $\mathrm{t}=0$ (before the treatment) and time $\mathrm{t}=1$ (after the treatment). $\mathrm{j}=1,2,3 \ldots . . \mathrm{J}$, where $\mathrm{J}$ is the number of firms in the sample. $\mathrm{X}_{\mathrm{ijt}}$ is a vector of the characteristics of the units under study at time $t$ (before the treatment). Given the data available, in the present study this vector only has variables that change across firms so that $\mathrm{X}_{\mathrm{ijt}}=\mathrm{X}_{\mathrm{jt}}$. The dummy variable $\mathrm{d}_{\mathrm{i}}$ is 1 for observations belonging to the treatment group and 0 for observations belonging to the control group (when comparing the two control groups, $d_{i}$ is 1 for the younger group).

$\beta$ is the parameter of interest and captures the difference between the proportional change in the treatment group's average real hourly wage and the proportional change in the control group's average real hourly wage ${ }^{16}$. The $\beta$ estimated corresponds to the difference in differences estimator which is given by:

$\hat{\beta}^{D D}=\left.\Delta \bar{W}_{i j t}\right|_{i=1}-\left.\Delta \bar{W}_{i j t}\right|_{i=0}$, the difference between the time differences of the sample means of the treatment and the control group.

As the new law was enforced from January 1987, the average wage of the treatment group is expected to rise markedly between 1986 and 1987 (the survey data refers to March of each year). In this way, in the period before the treatment (March 1986) the new law was completely unforeseeable, while in $t=1$ (March 1987) 3 months had elapsed since the new statutory MW, time enough to adjust wages, before major adjustments in employment levels. Note that although this study is perhaps focusing on the most flexible part of the workforce, the Portuguese labour market is known for being rather rigid in terms of employment, and considerably flexible in terms of wages. (Cardoso, 1997).

16 Note that this difference is computed by using firms that have workers of the relevant age group both before and after the treatment, so that a value for the average wage is given. For example, in a regression using the two younger groups, $\beta$ gives the difference in the average proportional wage change of the 18 and 19 year old workers in those firms that had these young workers before and after the treatment, with the same measure for 20 to 25 year old workers in the firms that had those older workers before and after the treatment. 
The first row of table 1 shows the difference between the proportional wage ${ }^{17}$ change of the 18 and 19 year old workers and the one of 20 to 25 year old workers. From 1986 to 1987 the very young workers had a percent wage increase that exceeded the one of young adults by 7.2 points. If this was a general trend of those years, one would expect that by extending the time lag to two or three years, this number would increase ${ }^{18}$. Instead, and coherent with my claim that teenagers' wages experienced an exogenous shock between 1986 and 1987, the difference does not increase, on the contrary, it amounts to no more than 5.8 points for a two year lag and 5.7 points for a 3 year lag.

The second row repeats the analysis for the older control group. Again, the proportional wage increase of the target group is higher when just one single year interval is considered, the one that encloses the MW change. From a percent increase 6.6 points higher than the one of workers aged 30 to 35, this value fades away to 6 and 4.5 points when two and three year lags are used.

It is also reassuring to observe that between the two control groups, there are no significant differences in their percent wage changes, whatever the time interval considered. In this way, the evidence points to a particular proportional wage increase circumscribed to the 18 and 19 year old workers only and exactly between the two time periods between which the MW change took place ${ }^{19}$.

17 Real hourly average wages were obtained by summing up the total monthly real wages for normal hours with the total monthly real wages for overtime and dividing this number by the sum of average monthly hours with overtime hours.

18 I actually estimated the difference between the proportional wage change for the various combinations of groups of workers for the intervals 1987 to 1988 and 1988 to 1989 . None of the coefficients obtained was insignificantly different from zero, except the one that compared teenagers with young adults' proportional wages for the period 1987 to 1988. This difference was estimated to be 0.0165 (with a standard error of 0.005 ), and so was very low when compared to the one of the 1986 to 1987 interval.

19 Similar regressions were run using as dependent variable the differences in log wages. The results were similar to the ones of proportional wage changes. The same exercise was done using as dependent variable difference in wage levels. In this case, one could observe that the target group's wages suffer a sharp rise from 86 to 87 in its average real hourly wage level, when compared to any of the other groups, and this rise diminishes if the time elapsed is extended. When the two control groups wages are compared the young adults' wages fall behind the ones of older workers, and this gap increases as time considered is extended. This result is not surprising, as both groups have similar percent increases in wages, which means that more experienced workers, with higher wages, would have higher absolute variations. 
Table 1: Differences in the proportional wage growth

\begin{tabular}{llll}
\hline Age groups pooled: & 1986 and 1987 & 1986 and 1988 & 1986 and 1989 \\
\hline (Dummy is 1 for first group pooled) & & & \\
$18-19$ and 20-25 & $0.072^{* *}$ & $0.058^{* *}$ & $0.057^{* *}$ \\
& $(0.005)$ & $(0.013)$ & $(0.010)$ \\
$18-19$ and 30-35 & $0.066^{* *}$ & $0.060^{* *}$ & $0.045^{* *}$ \\
& $(0.006)$ & $(0.013)$ & $(0.011)$ \\
$20-25$ and 30-35 & -0.005 & 0.001 & -0.010 \\
& $(0.004)$ & $(0.005)$ & $(0.007)$ \\
\hline
\end{tabular}

Note: Robust standard errors in parenthesis. All regressions use as control variables the following firms' characteristics: size, 19 industry dummies and 7 region dummies. The dependent variable is the time difference in the average hourly wage. ${ }^{20}$

$*$ - Significant at $5 \%$ level., ** - Significant at $1 \%$ level.

There is enough evidence supporting the assumption that the MW change with respect to the 18 and 19 year old workers at the centre of this study, has had a sizeable and real impact on this workers' wage distributions, representing therefore a binding restriction. The two control groups exhibit similar percent wage variations which is of particular relevance in this work. In fact, by using older workers in the firm as a control group, one risks using spurious variation due to ripple effects. By ripple effects here I mean the spillovers of an exogenous shock on some workers' wages on the remaining workers' wages. According to internal labour market theories, the structure of wages inside the firm may be rather insulated from market wages. Jobs that are filled with workers outside the firm are more likely to have competitive wages, while wages in jobs that are only reached through the promotion ladder, are probably designed to provide effort incentives, or to prevent high quit rates, leading to steeper career wage profiles. As such, the relative position of a job's wage on the wage structure of the firm may result from the firm's wage policy and the whole wage structure of the firm may change if there is an exogenous shock on the pay of a particular group of workers. Moreover, one would expect that the closer in the promotion ladder are the jobs to the ones that experienced the wage change, the more likely they are to be affected. In the particular case of this experiment, young adults' wages are more likely to be affected by this spillover effect than the older adults'. This could of course invalidate their use as a control group, as they would be prone to experience similar (though probably smaller) employment effects. This in turn would introduce a downward bias in the estimated

20 Number of Observations According to Groups Pooled and Years Used

\begin{tabular}{llll}
\hline Groups Pooled & 1986 and 1987 & 1986 and 1988 & 1986 and 1989 \\
\hline $18-19$ and $20-25$ & 15642 & 13386 & 12237 \\
$18-19$ and 30-35 & 14172 & 12198 & 10982 \\
$20-25$ and 30-35 & 20962 & 18584 & 16655 \\
\hline
\end{tabular}


impact of MW on teenagers employment, as the methodology used is based on comparing the outcomes in the control and treatment groups.

However, table 1 shows that the difference of teenagers wages' percent growth seems not to be lower with respect to the young adults group than with respect to the older control group. This evidence goes against the possibility that the spillover effect just described is of great importance ${ }^{21}$.

From the comparison of the proportional wage variations in the three age groups over time, not only it was possible to gather convincing evidence of the restrictiveness of the law change, but it also reinforced my claim that the control groups chosen are adequate, namely, that wage spillovers are probably of minor importance.

\section{Difference in differences: estimates of employment effects}

The econometric analysis will be based on the straightforward difference in differences. This is the name given to the before and after design with an untreated comparison group. Basically, the difference between the "after treatment" outcome and the "before treatment" outcome is computed for both the treatment and the control groups. The difference in differences is then the difference between these two measures. This technique has the clear advantage of differencing out all permanent individual characteristics of each group (through the "first difference"), as well as all other shocks or macroeconomic trends that affect both groups similarly ("second difference"). Firms' characteristics which are time invariant are differenced out by any of the differences. The result is the net impact of the treatment on the outcome for the treatment group.

The formulation used is the following:

21 One must keep in mind nevertheless, that similarly to other countries, a well documented wage inequality increase took place in Portugal during the eighties, favouring skilled workers (Cardoso, 1997). This means that the older group's wage variations, (even if age is not a perfect proxy for skill), may be affected by a time trend.

Given what has been said, it would still be possible that the wage estimates could suffer from downward bias as young adults wages could be inflated due to the spillover effect, and still the wage growth of teenagers against the one of young adults would not be much higher than when compared to older workers as the older group's wages growth would be persistently higher.

Being so, the fact that the third row of table 1 comparing the wage growth of the young adults with the one of 30 to 35 year old workers shows no evidence of statistically significant differences, would not give unambiguous information. It could be the result of similar wage growths with different sources: spillover effects for young adults and skill biased wage growth for older workers. However, the fact that whatever the time lag considered (1 to 3 years), the coefficients are persistently insignificant give no support to such interpretation as the spillover effect should fade away, while the older group's wage growth should be persistent. 


$$
\Delta Y_{i j t}=\alpha+\beta d_{i}+\gamma X_{j t}+\varepsilon_{i j t}
$$

where $\Delta Y_{i j t}$ is the change in the number of workers of age group $i$ in firm $j$ between time $\mathrm{t}=0$ (before the treatment) and time $\mathrm{t}=1$ (after the treatment). $\mathrm{j}=1,2,3 \ldots . ., \mathrm{J}$, where $\mathbf{J}$ is the number of firms in the sample. $X_{\mathrm{jt}}$ is a vector of the firm characteristics at time $\mathrm{t}=0$ (before the treatment). The dummy variable $d_{i}$ is 1 for observations belonging to the treatment group and 0 for observations belonging to the control group. $\beta$ is the parameter of interest and captures the difference between the change in the treatment group's average employment and the change in the control group's average employment. The difference in differences estimator is given by:

$$
\hat{\beta}^{D D}=\left.\Delta \bar{Y}_{i j t}\right|_{i=1}-\left.\Delta \bar{Y}_{i j t}\right|_{i=0},
$$

the difference between the time differences of the sample means of the treatment and the control groups. The key identifying assumption of this model is that in the absence of the treatment, the average employment change in both groups would be the same:

$$
\hat{\beta}^{D D}=0 \text { or } \mathrm{E}\left[\varepsilon_{i j t} \mid d_{i}\right]=0 .
$$

In practice the same regression was performed twice, one for each control group, using as dependent variable a pool of the employment changes in the treatment and one of the control group. As a robustness check the same regression was run for the 2 control groups, as if one of them was a treatment group. In this case, $\beta$ is expected to be insignificantly different from zero.

The dependent variable of equation (2) will be in separate regressions, the difference in the number of workers at specific age intervals and the difference in the total time worked by those workers.

As the above specification implies that in each regression there are 2 observations for each firm, the OLS standard errors are corrected by allowing nonindependence between the two observations of the same firm. A random effects model is used which allows for a correlation coefficient different from zero constant across firms.

With respect to the time difference, the following intervals will be investigated: [1986;1987], [1986;1988], [1986;1989], [average 1985 and 1986; average 1988 and 1989], [average 1985 and 1986; average 1987, 1988 and 1989].

Table 2 shows the difference in differences' coefficients for different age groups and time periods. The dependent variable is the difference in the total number of workers in the payroll of the firm for the age groups and time intervals considered. Each cell corresponds to a separate regression.

The sign of the coefficients in the first two rows clearly suggests a negative impact on the target group's employment. For all time intervals considered, the relative 20 
employment of 18-19s decreased when compared to 20-25s. Moreover, this effect seems to have persisted up to 1989. When the older control group is used, the coefficients are still estimated to be negative, though they only remain significant for the difference between 1986 and 1988.

Table 2:

Impact on the Number of workers

\begin{tabular}{llllll}
\hline Age groups & 1986 & 1986 & 1986 & $1985 / 86$ & $1985 / 86$ \\
(Dummy is 1 for 1st group) & 1987 & 1988 & 1989 & $1988 / 89$ & $1987-89$ \\
\hline $18-19$ and $20-25$ & $-0.087 * *$ & $-0.196 * *$ & $-0.223 * *$ & $-0.202 * *$ & $-0.173 * *$ \\
& $(0.020)$ & $(0.033)$ & $(0.041)$ & $(0.041)$ & $(0.036)$ \\
$18-19$ and 30-35 & -0.025 & $-0.107 * *$ & -0.010 & -0.100 & -0.087 \\
& $(0.020)$ & $(0.033)$ & $(0.056)$ & $(0.062)$ & $(0.055)$ \\
$20-25$ and 30-35 & $0.063 * *$ & $0.089 * *$ & $0.212 * *$ & 0.102 & 0.086 \\
& $(0.023)$ & $(0.037)$ & $(0.059)$ & $(0.064)$ & $(0.057)$ \\
& & & & & \\
Number of Firms & 23879 & 22014 & 20895 & 16685 & 15993 \\
Number of Observations & 47758 & 44028 & 41790 & 33370 & 31986 \\
\hline
\end{tabular}

Note: Robust standard errors in parenthesis. Other regressors are: size, 19 industry dummies and 7 region dummies. Region dummies are in most cases not significant, while other controls are. Firm controls just reduce slightly standard errors, not affecting the coefficients (see appendix I). With differences inside the firm, one should not expect these controls to change the difference in differences estimates.

* - Significant at $5 \%$ level.

** - Significant at $1 \%$ level.

For the 1986-1988 interval the employment growth of the group affected is smaller than the one of any of the control groups, so that there seems to be a clear negative employment impact. On average, the teenagers employment growth per firm was 0.196 workers less than the young adults' employment growth. Comparatively to the older group, however, teenagers' employment grew on average less 0.107 workers.

Turning to the difference in differences with the two control groups presented in the $3^{\text {rd }}$ row, the group of young adults had experienced a continuous employment increase compared to the older group of workers over the 1986-1989 period.

For the moment I will assume that the different age groups of workers do not follow different employment trends, so that all the changes observed are due to the change in the statutory minimum wage. That is to say that in the absence of the MW change, all coefficients would not have been significantly different from zero.

With this assumption, the fact that the young adults had an employment boost against any of the other groups would have been the result of a direct employment substitution effect. I argue that employment substitution effects are likely to occur between rather 
similar workers, in this case teenagers and young adults, and unlikely to occur between teenagers and workers aged 30 or more ${ }^{22}$.

The employment effect given by the difference in differences between the two younger groups would then be overestimated in absolute terms ${ }^{23}$, while the employment effect suggested by the older control group results would be a good approximation for the true employment effect.

Focusing on the interval 1986-1988 ( $2^{\text {nd }}$ column), the third coefficient would give the size of the substitution effect towards young adults in terms of average growth in the number of workers. The coefficient in the first row would then have to be corrected by deducting the substitution effect. By construction, the value obtained would be the one shown in the $2^{\text {nd }}$ row: -0.107 , and this would measure the true MW impact. That employment effect would correspond to a -0.4 employment-minimum wage elasticity for 18 and 19-year-old workers. A ten percent increase in this group of workers

22 Young adults (from 20 to 25 years) in the same firm as teenagers (aged 18 and 19) are likely to provide good controls, as they are not much different in terms of education, experience, tenure and skills. However, as we are clearly not dealing with independent labour markets, this will imply a large degree of substitutability between the two groups which may in turn introduce an element of bias. In fact, once the law enforces the same minimum wage for both groups of workers, it may be profitable to switch to the older group, as they have an advantage in terms of education, experience and tenure, though marginal it may be (note that wage profiles are quite steep in the begining of individuals' carrers, one hypothesis being the rapid accumulation of human capital, Borjas, 1996). This would imply a downward bias in the difference in differences estimates.

23 It has been mentioned in the previous section that the existence of wage spillovers (ripple effects) could underestimate the employment effect generated by the difference in differences regression between the two younger groups. I argued that these ripple effects did not seem to be of sizeable importance. The same does not seem to be true with respect to substitution effects. The debate will therefore be centred on the bias generated by employment substitution effects across age groups. However, as wage spillovers would lead to a smaller employment difference in differences between the target group and the younger control group, they would "smooth" the substitution effect. As it is, wage spillovers would bias the employment-minimum wage elasticity on the opposite direction of the substitution effect. The present analysis can be seen as considering the substitution effect from teenagers to young adults "net" of the impact of the potential wage spillover. 
statutory real minimum wage would generate a four percent decrease in this group's employment ${ }^{24}$.

The gross elasticity of substitution between young adults' employment and teenagers MW is $0.09^{25}$. So, in the present experiment a 10 percent increase in 18 and 19 year old workers minimum wage has generated a 0.9 percent increase in the young adults' employment, and a 4.0 percent decrease in teenagers' employment ${ }^{26}$.

The pattern of evolution suggested by the coefficients for different time intervals does not offer a clear-cut picture. If one looks at the results with the younger control group the treatment group's employment seems to fall until 1989. However, if one focus on the older control group, it seems to fade away after 1988. Various potential reasons could be put forwarded as to explain the dynamics of these employment effects.

In a before and after analysis however, the exact time periods chosen as period "before" and period "after" are crucial, and I acknowledge that if one allows for long intervals, not only is the ceteris paribus condition less likely to hold, but also spurious variation is likely to be amplified. Being so, at this point, the analysis will be restricted to the period considered the most adequate for the experiment.

Just as the possibility of occurrence of an employment substitution effect between groups of workers, an "income-type effect" might as well have taken place. The firm not only faced and exogenous change in the relative "price" of different workers, but it also suffered an exogenous increase in the total wage bill. The impact of the MW change on the treatment group employment that one ideally would like to estimate is the total impact, which includes both substitution ${ }^{27}$ and income effects. It is possible, however, that by the wage-bill effect alone the firm may reduce its whole workforce, either homogeneously or asymmetrically across different types of workers. As all variations that are homogeneously extended to the entire workforce will not be captured

24 The elasticity was calculated using the ratio given by -0.107 over $18-19$ year old workers average employment in 1986 (for the firms used in the regression: 0.785) and the percent variation in the real minimum wage for the same group of workers, to which I subtracted the percent change in the real MW for other workers: $-0.004=(0.107 / 0.785) /(35.5-1.6)$. If we did not subtract the change in the real statutory MW for other workers, and simply used the percent variation in the teenagers real minimum wage the elasticity would be 0.38 .

25 Calculations similar to the ones of direct elasticity: $0.0009=(0.089 / 2.798) /(35.5-1.6)$.

26 Given that we are using a quasi experiment it is obviously beyond the scope of this study trying to measure any kind of impact on the total employment.

27 Substitution effect is the one resulting from different relative prices for different types of workers. Note that the income effect as it is defined, may generate a labour-capital substitution effect 
by the present quasi experiment, the wage-bill effect could give rise to an underestimated employment elasticity.

Table 3 displays the coefficients for the impact on the number of hours worked by the total workforce of the relevant age groups. The conclusions derived before are entirely reinforced by these results. In fact, table 3 mimics table 2 in terms of both the significance and sign of the estimated coefficients.

Using alternatively each of these two measures of labour input (number of workers and number of hours worked) may generate different results. In fact, if there is an employment effect, for instance, a negative one, firms may either adjust mainly through firing and (not) hiring or may prefer to keep most of their workers and reduce their working time, introducing more part-time positions, etc. This is especially relevant for young workers, as there seems to be a considerable high share of part-timers, and usually part time work is associated with more flexible contract forms.

Table 3:

Impact on the number of hours worked

\begin{tabular}{llllll}
\hline Age groups pooled: & 1986 & 1986 & 1986 & $1985 / 86$ & $1985 / 86$ \\
(Dummy is 1 for first group) & 1987 & 1988 & 1989 & $1988 / 89$ & $1987-89$ \\
\hline $18-19$ and 20-25 & $-17.82^{* *}$ & $-46.86^{* *}$ & $-47.81^{* *}$ & $-45.25^{* *}$ & $-37.44^{* *}$ \\
& $(3.53)$ & $(5.82)$ & $(7.21)$ & $(7.28)$ & $(6.36)$ \\
$18-19$ and 30-35 & -5.22 & $-29.38^{* *}$ & -8.45 & $-25.54 *$ & $-20.30^{*}$ \\
& $(3.90)$ & $(6.36)$ & $(10.45)$ & $(11.75)$ & $(10.45)$ \\
$20-25$ and 30-35 & $12.60^{*}$ & $17.48^{*}$ & $39.36^{* *}$ & 19.70 & 17.14 \\
& $(4.29)$ & $(6.95)$ & $(10.72)$ & $(11.87)$ & $(10.58)$ \\
& & & & & \\
Number of Firms & 23879 & 22014 & 20895 & 16685 & 15993 \\
Number of Observations & 47758 & 44028 & 41790 & 33370 & 31986 \\
\hline
\end{tabular}

Note: Robust standard errors in parenthesis. Other regressors are: size, 19 industry dummies and 7 region dummies.

* - Significant at 5\% level.

** - Significant at $1 \%$ level.

Both adjustments (through hours worked per individual and through number of individuals) will be captured by using hours worked as dependent variable, but one will not be able to distinguish between them. On the other hand, when one uses changes in the number of employed people instead, one just estimates employment adjustments through hiring and firing.

Being so, table 3 not only provides some robustness check on the previous results, but can also bring some additional information. It is possible to compare the coefficients in similar positions in tables 2 and 3 by resorting to simple calculations. Table 2 showed that between 1986 and 1988 the average growth of the number of teenagers per firm 
was 0.196 workers lower than the growth of young adults'. These workers would have to be working 239 hours per month to generate an average loss of 46.86 in the number of hours if all employment adjustment had been made through hiring and firing. For the results obtained with the older control group this number is even higher (273.5 hours a month). As it is, there seems to be some evidence that teenagers' average working time suffered a reduction so that the employment impact is not completely captured by changes in the number of people working.

\section{Difference in differences: second experimental design ${ }^{28}$}

The second experimental design groups firms according to their likelihood of being affected by the MW change. If there is indeed an employment impact from the change in the MW, then it should be larger among those firms. A firm is more likely to be affected if the average wage paid to teenagers in 1986 is at or above the MW due to teenagers in 1986 and below the MW for adults in 1986. A dummy variable $A_{i}$ is introduced which takes the value 1 for firms more likely to be affected by the MW change and 0 otherwise.

The estimated regression also requires an interaction dummy variable $\mathrm{d}_{\mathrm{i}} \cdot A_{i}$ :

$$
\Delta Y_{i j t}=\alpha_{0}+\alpha_{1} A_{i}+\alpha_{2} d_{i}+\beta d_{i} \cdot A_{i}+\gamma X_{i j t}+\varepsilon_{i j t}
$$

The indexes $\mathrm{i} j$ and $\mathrm{t}$ have the same meaning as before. $\Delta \mathrm{Y}_{\mathrm{ijt}}$ is the change in the number of workers of age group $i$ in firm $j$ between time $t=0$ (before the treatment) and time $t=1$ (after the treatment). $X_{j t}$ is a vector of firm controls. As before, $d_{i}$ is 1 for observations in the treatment age group and 0 otherwise. The parameter $\alpha_{1}$ captures the difference in employment changes that are common to both age groups between firms more likely to be affected and firms less likely to be affected by the MW change. $\alpha_{2}$ summarises the way in which the difference in employment change between the two age groups is common to the two groups of firms. The parameter of interest, $\beta$ tests whether the difference in differences done before with the two age control groups is different for firms more likely to be affected by the MW change and firms less likely to be affected by the MW change. The identifying assumption is that if the difference between the employment time differences of teenagers and older workers is not related with the change in the law, then $\beta=0$. That is to say that assuming that certain firms are more likely to be affected by the change in the law than others, then if there is a negative impact on teenagers' employment as suggested by the previous results, this impact should be stronger in those firms.

28 The second experimental design tests whether the former different groups' employment were being driven by asymmetric omitted trends or variables. Still, the different age groups' employment evolution is depicted in Appendix II. 
One can also test whether different trends may be affecting asymmetrically the control groups' labour markets. Suppose one could separate firms in two groups: those affected by the MW change and those not affected. If $\alpha_{2}=0$, then all employment changes between two age groups would only take place in firms affected by the MW change. This would give a clear indication that the asymmetric behaviour between the control groups was due to the spillover effects and not to the existence of omitted variables or trends affecting the two control groups differently. In fact, the underlying assumption is that if these asymmetries arise because of omitted variables or trends unrelated with the MW change, then they should occur homogeneously across both types of firms.

Table 4:

Impact on the Number of workers using firms as control group

\begin{tabular}{|c|c|c|c|c|c|c|}
\hline \multirow[b]{3}{*}{ Dummy variables: } & \multicolumn{6}{|c|}{$\begin{array}{l}\text { Dependent variable: difference in number of workers between: } \\
\text { age groups: } 18-19 \text { and } 20-25 \quad \text { age groups: } 18-19 \text { and } 30-35\end{array}$} \\
\hline & 1986 & 1986 & 1986 & 1986 & 1986 & 1986 \\
\hline & 1987 & 1988 & 1989 & 1987 & 1988 & 1989 \\
\hline $\mathrm{d}_{\mathrm{i}}$ (1 if teenagers) & $\begin{array}{l}0.020 \\
(0.020)\end{array}$ & $\begin{array}{l}-0.035 \\
(0.033)\end{array}$ & $\begin{array}{l}-0.073 \\
(0.042)\end{array}$ & $\begin{array}{l}0.025 \\
(0.022)\end{array}$ & $\begin{array}{l}-0.011 \\
(0.036)\end{array}$ & $\begin{array}{l}0.090 \\
(0.063)\end{array}$ \\
\hline $\mathrm{A}_{\mathrm{i}}$ & $\begin{array}{l}0.434 * * \\
(0.090)\end{array}$ & $\begin{array}{l}0.585^{* *} \\
(0.139)\end{array}$ & $\begin{array}{l}0.377 * \\
(0.183)\end{array}$ & $\begin{array}{l}-0.004 \\
(0.067)\end{array}$ & $\begin{array}{l}0.134 \\
(0.106)\end{array}$ & $\begin{array}{l}0.146 \\
(0.174)\end{array}$ \\
\hline $\mathrm{d}_{\mathrm{i}} \cdot \mathrm{A}_{\mathrm{i}}$ & $\begin{array}{l}-0.886^{* * *} \\
(0.081)\end{array}$ & $\begin{array}{l}-1.278^{* *} \\
(0.121)\end{array}$ & $\begin{array}{l}-1.196^{* *} \\
(0.143)\end{array}$ & $\begin{array}{l}-0.411 * * \\
(0.062)\end{array}$ & $\begin{array}{l}-0.762 * * \\
(0.089)\end{array}$ & $\begin{array}{l}-0.803^{* *} \\
(0.114)\end{array}$ \\
\hline Number of Firms & 23879 & 22014 & 20895 & 23879 & 22014 & 20895 \\
\hline Number of observations & 47758 & 44028 & 41790 & 47758 & 44028 & 41790 \\
\hline $\begin{array}{l}\text { Number of observations } \\
\text { if } A_{i}=1\end{array}$ & 5786 & 5544 & 5228 & 5786 & 5544 & 5228 \\
\hline
\end{tabular}

Note: Robust standard errors in parenthesis. All regressions include the three dummies. Other regressors are: size, 19 industry dummies and 7 region dummies.

* - Significant at $5 \%$ level.

** - Significant at $1 \%$ level.

Table 4 presents the results of the difference in differences when firms are used as a control group, instead of relying solely on age group comparisons. Each column corresponds to a separate regression. The dependent variable is the difference in the number of workers between the relevant years for two of the age groups (as before, the two groups are pooled).

The coefficients are shown for the dummy variables. Again, the results point to a negative employment effect. Only $\mathrm{d}_{\mathrm{i}} \cdot A_{i}$ has a significant negative coefficient for all time intervals and for any of the two age groups. The fact that the $d_{i}$ coefficient is persistently not significant seems to indicate that the previous estimated employment impact which compared two age groups' employment variation is not a general problem being instead concentrated in those firms most affected by the new MW. Given these results, it seems rather unlikely that the initial estimations could have been seriously 
biased by possible exogenous trends affecting asymmetrically the various age groups' employment.

With this formulation it is now possible to decompose the difference in differences estimated before in two parts. The first one is the one that takes place in firms less likely to suffer the MW impact and the other one is the one that takes place in firms more likely to suffer the MW impact. The total difference between two age groups' employment change will be given by a weighted average of this two parts, where the employment changes in the two groups of firms is weighted by the proportion of firms belonging to each of the groups:

$$
\begin{aligned}
\hat{\beta}^{D D} & =\left.\Delta \bar{Y}_{i j t}\right|_{i=1}-\left.\Delta \bar{Y}_{i j t}\right|_{i=0}= \\
& =\alpha_{2} \frac{n_{1}}{n}+\left(\beta+\alpha_{2}\right) \frac{n_{2}}{n} \text { where } \mathrm{n}_{1} \text { is the number of firms less likely to }
\end{aligned}
$$

be affected by the MW change, $n$ is the total number of firms and $n_{2}=n-n_{1}$.

Table 5 gives the average employment effects in the two groups of firms using the results from table 4. The last row is a weighted average of the two previous rows in which the weights are the proportion of firms (or observations) belonging to the relevant groups. As expected, these numbers are exactly the same as the ones displayed in table 2.

Table 5:

Net employment effects

\begin{tabular}{lrlllllllll}
\hline & \multicolumn{1}{l}{ Employment difference in differences between: } \\
& $18-19$ and $20-25$ & \multicolumn{1}{c}{$18-19$ and 30-35 } & \multicolumn{2}{c}{$20-25$ and 30-35 } \\
\cline { 2 - 10 } Group of Firms & 1986 & 1986 & 1986 & 1986 & 1986 & 1986 & 1986 & 1986 & 1986 \\
$\mathrm{~A}_{1}=1\left(\beta+\alpha_{2}\right)$ & -0.866 & -1.313 & -1.269 & -0.386 & -0.773 & -0.713 & 0.480 & 0.540 & 0.556 \\
$\mathrm{~A}_{1}=0 \quad\left(\alpha_{2}\right)$ & 0,020 & $-0,035$ & $-0,073$ & 0,025 & $-0,011$ & 0,090 & 0.005 & 0.024 & 0.163 \\
weighted average & -0.087 & -0.196 & -0.223 & -0.025 & -0.107 & -0.010 & 0.063 & 0.089 & 0.212 \\
\hline
\end{tabular}

Table 5 provides us with rather interesting results. Firstly, the first 6 coefficients of the first row confirm that the bulk of the negative impact on teenagers' employment takes place mostly in the firms considered more likely to suffer with the change in the law. Secondly, the last 3 coefficients of the first row indicate that the increase in the employment of young adults with respect to older adults also seems to be concentrated in the same group of firms. This gives strong support for the initial hypothesis of a substitution effect towards young adults.

Finally, from the employment difference in differences between teenagers and older adults, the relative employment fall of the former is observable up to 1989, as it is when comparisons are made with the younger control group. The "fade away" phenomenon 
observed in the initial results occurs only in firms less likely to be affected by the MW change. This phenomenon is therefore probably driven by some omitted variable changing between 1988 and 1989, which is affecting the employment of young adults and is unrelated with the minimum wage change.

\section{Firms' entries and exits}

The fact that difference in differences is entirely based on firms that were observed before and after the change in the law may be a source of possible bias. In fact, by excluding from the analysis firms that died or were born after 1986 one risks to miss part of the picture of the employment evolution of the different age groups. New firms are very likely to absorb a disproportionately high share of younger workers, as there are no tenure gains associated with its workforce. Moreover, as it can be observed in table 2 in the appendix, entry and exit of firms is an important phenomenon in the Portuguese economy. Adding to that the simple fact that the working population inside the firms belonging to the panel is likely to get older, one has reasons to believe that the previous estimates were downward biased ${ }^{29}$.

As an attempt to deal with the problem just mentioned, the previous analysis will be extended to a representative sample of firms before the treatment and the outcomes will be compared with the ones of a representative sample after the treatment. The difference in differences has been defined as:

$$
\begin{aligned}
& \hat{\beta}^{D D}=\left.\Delta \bar{Y}_{i j t}\right|_{i=1}-\left.\Delta \bar{Y}_{i j t}\right|_{i=0}, \text { which is the same as: } \\
& \hat{\beta}^{D D}=\left.\bar{Y}_{i j t}\right|_{i=1, t=1}-\left.\bar{Y}_{i j t}\right|_{i=0, t=1}-\left[\left.\bar{Y}_{i j t}\right|_{i=1, t=0}-\left.\bar{Y}_{i j t}\right|_{i=0, t=0}\right],
\end{aligned}
$$

where the first difference is taken between groups in the same time period and only then time differences are taken between these two measures.

The same measure is now calculated using representative samples for $t=0$ and $t=1$. The period $t=0$ corresponds to the year of 1986 and the sample randomly selected includes firms remaining in subsequent years, which are the ones used so far in difference in

29 Further problems arise when omitting entrants and exitors from the analysis. In particular there may be an attrition bias as firms' destruction may not be an exogenous phenomenon. Firms may face unbearable wage pressure arising from the new minimum wage which forces them to shut down. In this case difference in differences would give upward biased estimates. Similarly, firms' creation may be endogenous. There may be less new firms after 1986 than otherwise would have been without the wage change. Unfortunately, it will not be possible to correct for these biases as there is no suitable instrumental variable to provide identifying restrictions to model attrition. 
differences, but also includes firms that will die after the treatment, exitors. The sample used for $\mathrm{t}=1$ is made of the firms that survive until $\mathrm{t}=1$ (in our study, $\mathrm{t}=1$ will correspond to 1987 and 1988 in separate regressions) together with all the firms that were born meanwhile.

Now the difference in differences estimator for the representative sample is:

$$
\begin{aligned}
& \hat{\beta}^{E E D}=\left.\bar{Y}_{i j t}^{P}\right|_{i=1, t=1}-\left.\bar{Y}_{i j t}^{P}\right|_{i=0, t=1}+\left.\bar{Y}_{i j t}^{I N}\right|_{i=1, t=1}-\left.\bar{Y}_{i j t}^{I N}\right|_{i=0, t=1}- \\
& -\left\{\left.\bar{Y}_{i j t}^{P}\right|_{i=1, t=0}-\left.\bar{Y}_{i j t}^{P}\right|_{i=0, t=0}+\left.\bar{Y}_{i j t}^{O U T}\right|_{i=1, t=0}-\left.\bar{Y}_{i j t}^{O U T}\right|_{i=0, t=0}\right\}
\end{aligned}
$$

In practice zeros are given to exitors' employment of any age group in $t=1$, and to entrants' similar variables in t=0 and regressions similar to (1) and (2) are estimated.

With this "difference in differences", permanent group (treatment and control groups) characteristics are still differenced out by taking differences between entrants and exitors $\left(\left.\bar{Y}_{i j t}^{I N}\right|_{i=1, t=1}-\left.\bar{Y}_{i j t}^{\text {OUT }}\right|_{i=1, t=0}\right)$. The same is true for macroeconomic trends that affect both groups similarly:

$$
\left(\left.\bar{y}_{i j t}^{I N}\right|_{i=1, t=1}-\left.\bar{y}_{i j t}^{O U T}\right|_{i=1, t=0}\right)-\left(\left.\bar{y}_{i j t}^{I N}\right|_{i=0, t=1}-\left.\bar{y}_{i j t}^{O U T}\right|_{i=0, t=0}\right)
$$

Also permanent firm characteristics are differenced out $\left(\left.\bar{Y}_{i j t}^{I N}\right|_{i=1, t=1}-\left.\bar{Y}_{i j t}^{I N}\right|_{i=0, t=0}\right)$.

However, the impact of variables that are both firm and group specific is not eliminated, as for entrants and exitors this method fails to take differences between two periods for the same group of workers inside each firm. Finally, if the number of entrants and exitors is not balanced, then group specific variables are not completely differenced out and additional spurious variation is introduced. In both time intervals considered there was a higher number of new firms being created than firms shutting down. As firms entering the market have on average more workers of any of the older age groups than workers in the treatment group, their contribution to the difference in differences estimator has a negative sign. In this case, not differencing out group specific variables would result in a negative bias in the difference in differences coefficient.

As a robustness check, a 2-step methodology is used to proxy the "missing employment values" in the representative samples. The basic idea is to produce a counterfactual for what would have been the various age groups' employment of an entrant or an exitor if it could have existed as such before the treatment.

The two-step procedure makes use of two samples of firms, one with firms which exit the market between 1985 and 1986 and the other with firms born in 1986. For each of these samples the employment of each of the age groups is regressed on a set of firm characteristics. The predicted values are then used to compute the employment levels, 
used in the difference in differences for entrants and exitors. This alternative way of obtaining employment values for the "blank years" reduces the impact of unobserved variables that are both firm and group specific as well as the effect of group specific variables coming from the difference in the number of entrants and exitors.

In both methods of proxying the employment differences for entrants and exitors, a similar equation to the previous ones is estimated:

$$
\Delta Y_{i j t}=\alpha_{0}+\hat{\beta}^{R D D} d_{i}+\not X_{i j t}+\varepsilon_{i j t}
$$

where $\hat{\beta}^{R D D}$ gives the difference in differences for the representative samples.

Table 6:

Impact on the Number of workers: panel of firms and representative samples' results compared

\begin{tabular}{|c|c|c|c|c|c|c|}
\hline \multirow[t]{4}{*}{ Age Groups } & \multirow{2}{*}{\multicolumn{2}{|c|}{$\begin{array}{l}\text { panel } \\
\text { original } \\
\text { results }\end{array}$}} & \multicolumn{4}{|c|}{ representative samples } \\
\hline & & & \multicolumn{2}{|c|}{$\begin{array}{l}\text { zeros for } \\
\text { counterfactual }\end{array}$} & \multicolumn{2}{|c|}{$\begin{array}{l}\text { 2-step } \\
\text { procedure }\end{array}$} \\
\hline & 1986 & 1986 & 1986 & 1986 & 1986 & 1986 \\
\hline & 1987 & 1988 & 1987 & 1988 & 1987 & 1988 \\
\hline $18-19$ and $20-25$ & $\begin{array}{l}-0.087 * * \\
(0.020)\end{array}$ & $\begin{array}{l}-0.196^{* * *} \\
(0.033)\end{array}$ & $\begin{array}{l}-0.083^{* *} \\
(0.016)\end{array}$ & $\begin{array}{l}-0.204 * * \\
(0.022)\end{array}$ & $\begin{array}{l}-0.075 * * \\
(0.016)\end{array}$ & $\begin{array}{l}-0.144 * * \\
(0.021)\end{array}$ \\
\hline $18-19$ and $30-35$ & $\begin{array}{l}-0.025 \\
(0.020)\end{array}$ & $\begin{array}{l}-0.107 * * \\
(0.033)\end{array}$ & $\begin{array}{l}0.013 \\
(0.016)\end{array}$ & $\begin{array}{l}-0.036 \\
(0.022)\end{array}$ & $\begin{array}{l}-0.012 \\
(0.016)\end{array}$ & $\begin{array}{l}-0.056^{* *} \\
(0.022)\end{array}$ \\
\hline $20-25$ and $30-35$ & $\begin{array}{l}0.063 * \\
(0.023)\end{array}$ & $\begin{array}{l}0.089 * \\
(0.037)\end{array}$ & $\begin{array}{l}0.096 * * \\
(0.018)\end{array}$ & $\begin{array}{l}0.168 * * \\
(0.025)\end{array}$ & $\begin{array}{l}0.063 * * \\
(0.018)\end{array}$ & $\begin{array}{l}0.088 * * \\
(0.025)\end{array}$ \\
\hline Number of Firms & 23879 & 22014 & 32871 & 37461 & 32871 & 37461 \\
\hline Number of Observations & 47758 & 44028 & 65742 & 74922 & 65742 & 74922 \\
\hline
\end{tabular}

Note: Robust standard errors in parenthesis. Other regressors are: 8 size dummies, 19 industry dummies and 7 region dummies.

* - Significant at $5 \%$ level.

** - Significant at $1 \%$ level.

Table 6 compares the results with the ones obtained when only the observations belonging to the panel were used. The signs of all but one coefficient remain the same. The coefficient comparing the employment growth of teenagers with the one of young adults does not change when zeros are used for the counterfactual, but is significantly lower in the 2-step procedure. When older adults are used as control group, while the coefficient referring to the period between 1986 and 1987 remains insignificant across all specifications, the one corresponding to the $1986-1988$ period decreases significantly for the representative samples. 
As 1986-1988 is probably the right time interval to consider, this result suggests that excluding exitors and entrants overstates the employment effects.

By estimating the following equation it is possible to have a more detailed picture of the separate contributions of entrants and exitors to the final result:

$$
\Delta Y_{i j t}=\alpha_{0}+\alpha_{1} d_{i}^{I N}+\alpha_{2} d^{I N}+\alpha_{3} d_{i}^{O U T}+\alpha_{4} d^{O U T}+\beta d_{i}+\gamma X_{i j t}+\varepsilon_{i j t}
$$

The dummy variable $\mathrm{d}^{\mathrm{IN}}$ takes the value 1 if the firm is an entrant and 0 otherwise. The interaction dummy $d_{i}{ }^{I N}$ is 1 if the difference in employment refers to the control group of an entrant and 0 otherwise. $\mathrm{d}_{\mathrm{i}}{ }^{\text {OUT }}$ and $\mathrm{d}^{\text {OUT }}$ are similar dummy variables for exitors.

The parameters $\alpha_{2}$ and $\alpha_{4}$ capture the extent to which entrants and exitors' average employment changes of both age groups are different from the remaining firms. The coefficients $\alpha_{1}$ and $\alpha_{3}$ summarise the way in which the difference in employment change between the two groups among entrants and exitors is dissimilar to the one of firms in the panel. $\beta$ captures the MW impact on the treatment group employment in the panel of firms as the different impacts of entrants and exitors is picked up by the other dummy variables. Therefore, $\beta$ is the same coefficient as the one estimated in (1). $\hat{\beta}^{R D D}$ can be decomposed as follows:

$$
\hat{\beta}^{R D D}=\beta \frac{m_{1}}{m}+\left(\beta+\alpha_{1}\right) \frac{m_{2}}{m}+\left(\beta+\alpha_{3}\right) \frac{m_{3}}{m}
$$

where $m_{1}$ is the number of firms in the panel, $m_{2}$ is the number of entrants, $m_{3}$ is the number of exitors and $\mathrm{m}$ is the total number of firms.

Table 7 displays the decomposition of the employment impact among firms in the panel, exitors and entrants. The coefficients in first row (panel of firms) are the same as the ones shown before in table 2. Last row shows the difference in differences estimates for the representative sample. When zeros are used for the counterfactual (table 7a), exitors contribution to the relative employment of teenagers has a positive sign, while entrants' contribution has a negative sign. In practice this simply means that both new firms and firms close to leaving the market employ less teenagers than any of the older groups of workers. As the difference between teenagers' and young adults employment is similar for both exitors and entrants, the impact of these groups of firms cancel out.

However, if one uses older workers as control group, teenagers are outnumbered by older workers to a much larger extent among exitors than among entrants ${ }^{30}$. This drives

30 One expects that to happen as older firms are more like to have an older workforce, for the reasons already mentioned. 
the coefficient corresponding to period 1986 to 1988 down from -0.107 to $-0.036^{31}$. In the 2-step procedure exitors' contribution to the employment effect has a negative sign, although it is less negative than the one of the panel. This implies that the average employment difference between teenagers and any of the older groups is larger than it was in firms that exited in 1986. Also, the coefficients corresponding to the new-born firms is never as negative as the one of the panel.

Table 7:

Net employment effects

(a) zeros for counterfactual

\begin{tabular}{lllll}
\hline Group of Firms & \multicolumn{2}{l}{$18-19$ and $20-25$} & \multicolumn{2}{l}{$18-19$ and $30-35$} \\
& $1986-1987$ & $1986-1988$ & $1986-1987$ & $1986-1988$ \\
\hline Panel $\beta$ & -0.087 & -0.196 & -0.025 & -0.107 \\
Entrants $\left(\beta+\alpha_{1}\right)$ & -0.706 & -0.846 & -0.160 & -0.225 \\
Exitors $\left(\beta+\alpha_{3}\right)$ & 0.698 & 0.804 & 0.441 & 0.538 \\
weighted average & -0.083 & -0.205 & 0.013 & -0.036 \\
\hline
\end{tabular}

(b) 2-step procedure

\begin{tabular}{lllll}
\hline Group of Firms & \multicolumn{2}{l}{$18-19$ and $20-25$} & \multicolumn{2}{l}{$18-19$ and $30-35$} \\
& $1986-1987$ & $1986-1988$ & $1986-1987$ & $1986-1988$ \\
\hline Panel $\beta$ & -0.087 & -0.196 & -0.025 & -0.107 \\
Entrants $\left(\beta+\alpha_{1}\right)$ & 0.007 & -0.065 & 0.055 & 0.029 \\
Exitors $\left(\beta+\alpha_{3}\right)$ & -0.101 & -0.075 & -0.021 & -0.004 \\
weighted average & -0.075 & -0.144 & -0.013 & -0.056 \\
\hline
\end{tabular}

Representative sample results provide the lower boundaries for the employment impact resulting from the teenagers minimum wage increase. Focusing on the interval between 1986 and 1988 and at the regressions using older adults as control group, the employment elasticity ${ }^{32}$ is -0.2 when zeros are used as counterfactual and -0.26 in the 2 -step methodology. Given the possibility of selective attrition, the true employment

31 One must be careful about the validity of the control groups under this circumstances. Indeed, it is difficult to argue that the magnitude of the employment difference in differences between 1986 and 1988 for the two adult groups, 0.168 (table 6, row 3, column 4) is due to the substitution effect.

32 When zeros were given to the counterfactuals, the elasticity was calculated using the ratio given by -0.036 over the average number of $18-19$ year old workers average employment in 1986 (because of the zeros introduced, the mean is smaller than the one in previous calculations: 0.519) and the percent variation in the real minimum wage for the same group of workers (35.5), to which we subtracted the percent change in the real MW for other workers $(1.6):-0.2=(-0.036 / 0.519) /(35.5-1.6) \times 100$. The same calculations give the following result for the two-step methodology:

$-0.26=(-0.056 / 0.627) /(35.5-1.6) \times 100$. 
elasticity is expected to lie somewhere in the interval between -0.2 and the original value, -0.4 .

\section{Conclusion}

Portugal offers extraordinary conditions to evaluate the impact of Minimum Wages (MW) on teenagers' employment following a "quasi-experiment" analysis. First, the change in the law in the MW of the 18 and 19 years old workers in January of 1987 proved to have had a clear binding effect on these workers' wages. Secondly, the use of older workers as control groups seems to have given good results. Thirdly, the possibility of using a large dataset of microdata gives this study a comparative advantage with respect to previous studies.

The estimated results show that the abolition of $25 \%$ of the MW reduction for teenagers had a significant and negative impact on teenagers' employment. This impact seems to have persisted for more than 2 years. It was also provided evidence of a substitution effect towards workers aged 20 to 25 years old. These results are rather robust to two experimental designs which hinge on different assumptions. There is some indication that employment adjustment is done both by reducing the number of teenagers employed and the time worked by those who remain employed.

The results obtained point to an elasticity among the highest (in absolute terms) found in the literature. The values found were in the range -0.20 to -0.40 . I believe that this might be the case because what is at stake is the impact of a very large change in the MW, because the study focus on very young workers (expected to be among those with lowest productivity) and also because Portugal during the 80's had a rather high MW average wage ratio. The economic conditions of the period are unlikely to have been responsible for the negativity of estimated elasticity, as Portugal was experiencing a period of economic recovery and employment expansion.

This work supports the idea that negative employment effects are probably higher among teenagers than among adults and that some substitution effect towards workers with higher marginal productivity is likely to occur. 


\section{References}

Abowd, John M., F. Kramarz, T. Lemieux and D. Margolis, 1997. Minimum Wages and Youth Employment in France and the United States. National Bureu of Economic Research, Working Paper 6111.

Bazen, S., Skourias, N., 1997. Is There a Negative Effect of Minimum Wages on Youth Employment in France?. European Economic Review 41, 723-732.

Belman, Dale, Wolfson, Paul, 1996. A Time Series Analysis of Employment and the Minimum Wage. Mimeo.

Blanchard, Olivier, and Jimeno, Juan, 1995. Structural Slumps and Persistent Unemployment - Structural Unemployment: Spain Versus Portugal. American Economic Review 85, 212-18.

Brown, Charles, C. Gilroy and A. Kohen, 1982. The Effect of the Minimum Wage on Employment and Unemployment. Journal of Economic Literature 10, 487-528.

Card, D., 1992a. Do minimum wages reduce employment? A case study of California, 1987-1989. Industrial and Labour Relations Review 46, 38-54. 1992b. Using regional variation in wages to measure the effects of the Federal minimum wage. Industrial and Labour Relations Review 46, 22-37.

1994. Do Minimum Wages Reduce Employment? A case Study of the Fast Food Industry in New Jersey and Pennsylvania. American Economic Review 84, 772-93.

Card, D., Katz, L., and A. Krueger, 1994. Comment on David Neumark and William Wascher, Employment Effects of Minimum and Subminimum Wages: Panel Data on State Minimum Wage Laws. Industrial and Labour Relations Review 47, 48797.

Card, D. and Krueger, A., 1998. A reanalyses of the effect of the New Jersey minimum wage increase on the fast food industry with representative payroll data. National Bureau of Economic Research, working paper 6386.

1995. Myth and Measurement - The New Economics of the Minimum Wage. (Princeton University Press, Princeton, NJ).

Cardoso, Ana Rute, 1994. Regional Wage Inequality. Mimeo. , 1995. Workers or Employers: Who is Shaping Wage Inaquality?. Mimeo. 1997. Earnings Inequality in Portugal: the Relevance and the Dynamics of Employer Behaviour. European University Institute, Florence. PhD Thesis.

Dickens, Richard, Machin, Stephen, Manning, Alan, Wilkinson, David, 1995. What Happened to Wages and Employment After the Abolition of Minimum Wages in Britain?. Mimeo.

Dickens, Richard, Manning, Alan, 1995. After Wage Councils. New Economy, 223-27.

Dolado, Juan, F. Kramarz, S. Machin, A. Manning, D. Margolis and C. Teulings, 1996. The Economic Impact of Minimum Wages in Europe. Economic Policy, October, 319-72.

Dolado, J., Felgueroso, F., Jimeno, J., 1997. The effects of minimum bargained wages on earnings: evidence from Spain. European Economic Review 41, 713-721. 
Evans, W. and Turner, M., 1995. Employment Effects of Minimum and Subminimum Wages: Comment. The Urban Institute, Washington. Mimeo.

Guimarães, P., Portugal, P., 1996. The Influence of Local Labor Market Conditions on the Entry and Exit of Plants. Mimeo.

Kaitz, Hyman, 1970 Experience of the Past: the National Minimum, Youth Unemployment and Minimum Wages, Bulletin 1657, U.S. Department of Labor, Bureu Of Labor Statistics.

Katz, L. and Krueger, A., 1992. The Effect of Minimum Wage in the Fast Food Industry. Industrial and Labour Relations Review 46, 6-21.

Lang, K. and Kahn, S., 1998. The Effect of Minimum-Wage Laws on the Distribution of Employment: Theory and Evidence. Journal of Public Economics 69, 67-82.

Linneman, Peter, The Economic Impacts of Minimum Wage Laws: A New Look at an Old Question. Journal of Political Economy 90, 443-69.

Machin, S. and Manning, A., 1994. The Effects of the Minimum Wages on Wage Dispersion and Employment: Evidence from the U. K. Wages Councils. Industrial and Labour Relations Review 47, 319-329.

1996. Employment and the Introduction of a Minimum Wage in Britain. The Economic Journal 106, 667-76.

, 1997. Minimum wages and economic outcomes in Europe. European Economic Review 41, 733-742.

Meyer, B., 1995. Natural and Quasi-Experiments in economics. Journal of Business and Economic Statistics 13, 151-206.

Ministério do Emprego e da Segurança Social, Departamento de Estudos e Planeamento, unpublished information.

Neumark, D. and Wascher, W., 1992. Employment Effects of Minimum and Subminimum Wages: Panel Data on State Minimum Wages. Industrial and Labour Relations Review 46, 55-81. ,1994. Employment Effects of Minimum and Subminimum Wages: Reply to Card, Katz and Krueger. Industrial and Labour Relations Review 47, 497-512. , 1996. "The Effect of New Jersey's Minimum Wage Increase on Fast-Food Employment: A Re-Evaluation Using Payroll Records". Michigan State University. Mimeo,

OECD Employment Outlook, June 1998.

Pimentel, Pedro, 1995. O Salário Mínimo em Portugal. Universidade Nova de Lisboa, faculdade de Economia. Tese de Mestrado.

Portuguese legislation: Diário da República.

Quarterly Bulletins of Bank of Portugal, 1985-1988.

Review Simposium on "Myth and Measurement: The New Economics of Minimum Wage", 1995. Industrial and Labour Relations Review 48, 827-849.

Ribeiro, Eduarda, 1993. Le Salaire Minimum au Portugal: Les Incidences Sur L'Emploi. Employment Ministry, Portugal.

Schmitt, John and J. Bernstein, 1997. Three Tests of the Employment Impact of the October 1996 Increase in the U. S. Minimum Wage. Economic Policy Institute, Washington. Mimeo. 
Wellington, A. The Effects of the Minimum Wage on the Employment Status of Youths: An Update, Journal of Human Resources 26, 27-46.

Zavdony, Madeline, 1996. Correcting for the Endogeneity of Minimum Wages. Mimeo. 


\section{Appendix I}

\section{Minimum Wages in Portugal: institutional setting and historical development}

Statutory minimum wages were introduced in Portugal in 1974 following the democratic revolution in the same year. Nowadays called RMMG (Remuneracao Minima Mensal Garantida), MW have undergone through several transformations. By the end of the 70's there were three different RMMG - for domestic work, agriculture and other activities - established at the national level ${ }^{33}$. Moreover, these levels were supposed to be revised on a year basis. In fact, with the exception of 1982 and 1989 this has been the case.

Every year, an interministerial team proposed the new levels that would then be discussed in the parliament. From 1984, these values were submitted to the Economic and Social Council appreciation (ESC). Its members were the Government, the two workers confederations ${ }^{34}$ and the three employers' confederations. In this manner, the various social factions would have a word to say, even though the final decision was carried by the government.

According to approximate estimates, the percentage of non-agricultural workers paid close to the RMMG followed a decreasing trend during the eighties attaining a value close to $9 \%$ in 1987.

33 There are also minimum wages established by collective bargaining contracts or agreements between the various possible bargaining levels: one or several unions of workers, federations (base-unions associated by economic activity) or "unioes" (baseunions associated by geographical area) with firm(s) or employers' unions. They have, nevertheless to comply with the RMMG, having the freedom to set higher minimums for particular regions, industries, set of firms or occupations. In spite of that, and as will be made clear in the empirical analysis section, the RMMG are a major constraint on the wage distribution of workers. In fact, as negotiations for bargaining contracts or agreements often begin before the establishment of the RMMG, it is not unusual that they end up by being set below the national minimum, which becomes a binding restriction. Being so, for the relevance of the present study there is no great loss in not taking into account the RMMG

34 Confederations are national associations of base-unions. There are two workers' confederations in Portugal, CGTP comprising 150 base unions (and an estimated number of 1 million workers) and UGT gathering 49 unions (and an estimated number of just over 1 million workers), (Pinto, 1990). There are three employers' confederations (national level associations) defined according to the broad economic sectors: agriculture, industry and trade. 
For the purpose of the study at hand, the various partial exemptions of the RMMG and their changes through time were thoroughly scanned. These have been related with teenage workers, apprentices, small firms and, in some cases, handicapped workers.

Reductions for handicapped workers remained valid up to now. Partial exemptions to apprentices suffered changes both in the maximum age applicable and in the percentage of exemption. However, these variations do not seem promising in terms of providing conditions for a natural experiment because of the small number of apprentices at the minimum wage level for those ages. Though for different reasons, the same applies to agricultural firms for which a specific RMMG ceased to apply in 1991. First of all, the main data source (described below) hardly covers the agricultural activity. Additionally, the gap between the agriculture RMMG and the non-agricultural one has been diminishing gradually until its abolishment. Though not crucial, one final motive would be related with the measurement of agricultural wages in Portugal, which is known as imprecise due to the generalised use of non-monetary payments.

Also firms with 5 or less workers or firms with less than 50 workers who claimed to be subject to an unbearable rise in labour costs were partially exempted, for they would just be enforced to pay the agricultural RMMG (a lower wage). From these, the later do not offer an opportunity for a before/after analysis: they simply cannot be identified. The small firms can be studied under this perspective. We will nevertheless chose other change in the minimum wage law because this change is not as large as it would be desirable as the agricultural RMMG has been gradually pushed towards the general RMMG, as mentioned above. In fact, when in 1991 the agricultural RMMG was abolished, this was already $98.6 \%$ of the non-agricultural RMMG.

Finally, from the exemptions related with young workers, the change occurred in January of 1987 with respect to 18 and 19 years old workers was certainly the most appropriated for a "natural experiment"35. Up to that date, the total amount of RMMG was due to workers with at least 20 years old. From then onwards, workers aged 18 and 19 years old were entitled the complete RMMG instead of the $75 \%$ received before ${ }^{36}$.

35 The 17 year old workers reduction in the statutory minimum wage was changed as well: before 1987 it was $50 \%$ and from that time on was $25 \%$.

36 Some exceptions were allowed: for handicapped workers reductions for up to $50 \%$, for apprentices $20 \%$ reductions for no more than two years and only in exceptional circumstances. Finally, firms with less than 5 workers could pay the agricultural RMMG ( $88 \%$ of the non-agricultural RMMG in 1987). This was already possible since the late 70 's, although the bureaucratic process was made simpler in 1987. Still, these small firms were now required to pay the full agricultural minimum wages to workers aged 18 or more and not 20 or more as before. 


\section{Economic Setting}

The year of 1986 corresponds to the beginning of the economic expansion following the harsh times that took place in Portugal during the first half of the decade. In fact, inflation had been almost 30\%, the public deficit had been absorbing 10\% of GDP and there had been persistent current external deficits. The GDP growth rate was negative in 1984 and the investment component of GDP reached $-17 \%$ in that same year. This scenario is partially explained by the second oil shock impact as well as the economic policy followed from 1980 to 1982 under the influence of the political electoral cycle. Portugal had to go through its second IMF stabilisation programme and the macroeconomic results of the restrictive measures were rather successful. By 1986 a trend of economic expansion had just started, helped by the loosening of the restrictive economic policies.

The period 1986-1988 was also characterised by a series of favourable events in the international arena. These are mainly the fall in oil prices, the depreciation of the dollar, the reduction of the international interest rates and the substantial net inflow of transfers from the EEC. EEC membership from 1986 also had a positive impact on exports, investment and consumption through expectations of a rise in permanent income. The recovery of economic activity, already noticeable throughout 1985 has been sustained during 1986,1987 and 1988 with a positive impact on the labour market. In fact, a significant downward trend in the unemployment rates started in 1986. Note nonetheless that during the period 1983-1986 both the active population and the employment decreased. The explanation put forward is that there might have been a discouraged worker effect (OECD, 1986: 37; Cardoso, 1997: 7). Only in 1989 the active population rise to 1986 levels, while employment in 1988 had already gone just over its 1983 value.

Given what has been said, in the period of analysis there is an expansion of the active population, possibly with workers re-entering the labour market. It is however a period of high growth in investment, exports and economic activity, so that the employment growth is enough to generate a fall in the unemployment rate.

Related with the general economic conditions of the period under analysis, recent literature has suggested that the timing of implementation of policies affecting the labour market may be determinant to both short run and long run impacts (Blanchard, 1985). The conclusions of the present study have to be framed accordingly. 


\section{Appendix II}

\section{Employment evolution by age groups}

In order to investigate possible omitted trends underlying the different age groups' employment one can look at employment evolution (figure 2) and total employment changes (figure 3) by age intervals. Note that unfortunately it has not been possible to get data on exactly the same age intervals of the present study. In particular, the younger group is much broader as it includes workers as young as 15 .

Figure 2: Total employment by age groups ${ }^{37}$.

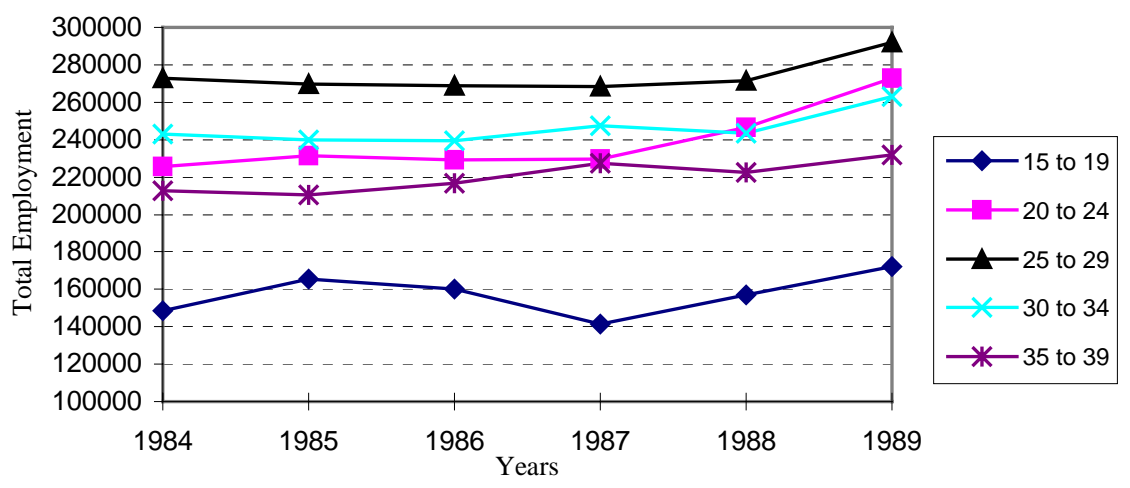

Source: Quadros de pessoal, DEMQE.

From figure 2 we can see that in general the different age groups have rather approximate evolution with a few differences, better captured by figure 3 which gives employment changes by age groups. It becomes clear that the younger group of workers experiences stronger employment fluctuations. It is also apparent that the two younger groups have a quite approximate evolution. Indeed, the two younger groups employment seems to vary independently from the older groups' one.

One can guess that if it would possible to gather separate data for the group of 18 and 19 year old workers, these similarities with the 20 to 24 years old workers would be even stronger, as the employment of the very young workers is likely to be the less stable, being related with getting in and out of the education system.

37 Total employment is defined as total number of workers in the payroll of all Portuguese firms. 
From 1986 to 1987 the younger group's employment falls sharply, while the older groups employment remains stable for people in their twenties and increases for people in their thirties. The subsequent teenagers employment increase in 1988 fails to fully compensate the previous fall. It will be difficult to argue against the possibility that the this slump is due to the 1997 increase in the statutory minimum wage for workers aged between 18 and 19 and also workers aged $17^{38}$.

Figure 3: Variation in total employment by age groups.

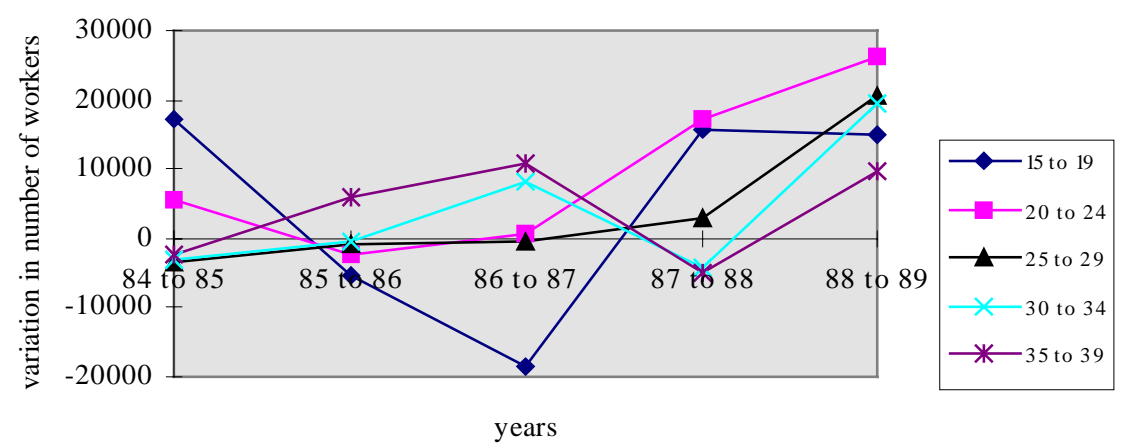

Source: Quadros de pessoal, DEMQE.

From the above figures it seems that while the evolution of adults' employment is closer to the one of younger adults, the individuals aged 30 to 34 experience smaller fluctuations. As it will be mentioned below, there is probably a trade off between using one group or the other, as the most similar group is also the group whose evolution is most likely to be associated with spillover and substitution effects. We would further argue that this slight divergence may enhance robustness if comparisons using each of control groups turn out to reach similar results.

3817 years workers were entitled $50 \%$ of the adults' minimum until 1986 and $75 \%$ since January 1997. 


\section{Appendix III}

Table1:

Panel of the Firms Sampled in 1986

\begin{tabular}{llllll}
\hline & 1985 & 1986 & 1987 & 1988 & 1989 \\
\hline Number of firms & 25868 & 32031 & 26032 & 23941 & 22655 \\
Average size & 20.12 & 17.24 & 19.97 & 21.18 & 22.7 \\
Average n. workers 18-19 years old & 0.79 & 0.675 & 0.75 & 0.805 & 0.84 \\
Average n. workers20-25 years old & 2.78 & 2.43 & 2.81 & 2.97 & 3.155 \\
Average n. workers 30-35 years old & 2.97 & 2.54 & 2.98 & 3.19 & 3.29 \\
Average n. women 18-19 years old & 0.27 & 0.236 & 0.276 & 0.304 & 0.314 \\
Average n. women 20-25 years old & 1.08 & 0.983 & 1.131 & 1.217 & 1.307 \\
Average n. women 30-35 years old & 1.046 & 0.941 & 1.11 & 1.21 & 1.24 \\
Average monthly hours by 18-19s & 49.5 & 45.15 & 47.57 & 50.84 & 50.69 \\
Average monthly hours by 20-25s & 94.01 & 89.5 & 94.77 & 99.67 & 99.03 \\
Average monthly hours by 30-35s & 80 & 76.11 & 83.47 & 91.48 & 89.08 \\
Average hourly wage of 18-19s & 97.7 & 117.5 & 139.03 & 154.79 & 178.98 \\
Average hourly wage of 20-25s & 122.3 & 147 & 168.06 & 187.8 & 215.7 \\
Average hourly wage of 30-35s & 148.19 & 177.79 & 205.86 & 227.4 & 270 \\
Number of firms with 18-19s & 7295 & 8353 & 7068 & 6761 & 6396 \\
Number of firms with 20-25s & 14029 & 16832 & 14303 & 13406 & 12693 \\
Number of firms with 30-35s & 11880 & 14217 & 12575 & 12295 & 11397 \\
Number of firms with 18-19s \& 20-25s & 5689 & 6383 & 5653 & 5466 & 5270 \\
Number of firms with 18-19s \& 30-35s & 4792 & 5330 & 4814 & 4799 & 4532 \\
Number of firms with 18-19s \& 20-25s & 8162 & 9498 & 8595 & 8532 & 8018 \\
\hline
\end{tabular}


Table 2:

Impact on the Number of workers

\begin{tabular}{lllllll}
\hline & 1986 & 1986 & 1986 & $1985 / 86$ & $1985 / 86$ & Includes \\
& 1987 & 1988 & 1989 & $1988 / 89$ & $1987-89$ & Controls \\
\hline $18-19$ and $20-25$ & $-0.069 * *$ & $-0.133^{* *}$ & $-0.189 * *$ & $-0.140^{* *}$ & $-0.119^{* *}$ & No \\
& $(0.026)$ & $(0.059)$ & $(0.052)$ & $(0.068)$ & $(0.060)$ & \\
$18-19$ and 30-35 & -0.032 & $-0.113^{* *}$ & -0.029 & $-0.108^{*}$ & $-0.094 *$ & No \\
& $(0.022)$ & $(0.035)$ & $(0.059)$ & $(0.062)$ & $(0.055)$ & \\
$20-25$ and 30-35 & 0.037 & 0.019 & $0.160 * *$ & 0.032 & 0.026 & No \\
& $(0.032)$ & $(0.066)$ & $(0.075)$ & $(0.089)$ & $(0.078)$ & \\
$18-19$ and 20-25 & $-0.069 * *$ & $-0.133 * *$ & $-0.189 * *$ & $-0.140 * *$ & $-0.119 * *$ & Yes \\
& $(0.024)$ & $(0.051)$ & $(0.052)$ & $(0.059)$ & $(0.051)$ & \\
$18-19$ and 30-35 & -0.032 & $-0.113 * *$ & -0.029 & $-0.108 *$ & $-0.094 *$ & Yes \\
& $(0.022)$ & $(0.035)$ & $(0.059)$ & $(0.061)$ & $(0.054)$ & \\
$20-25$ and 30-35 & 0.037 & 0.019 & $0.160 * *$ & 0.032 & 0.026 & Yes \\
& $(0.031)$ & $(0.058)$ & $(0.074)$ & $(0.080)$ & $(0.070)$ & \\
Number of firms & 26032 & 23944 & 22655 & 18023 & 17278 & - \\
Number of observations & 52064 & 47887 & 45310 & 36046 & 34556 & - \\
\hline
\end{tabular}

Table 3:

Firm entries and exits

\begin{tabular}{rlllll}
\hline \multicolumn{1}{r}{ Period t-1: } & 1984 & 1985 & 1986 & 1987 & 1988 \\
Period t: & 1985 & 1986 & 1987 & 1988 & 1989 \\
\hline Number of firms (t-1) & 89550 & 93988 & 98027 & 101485 & 111970 \\
Share of entrants (t-1, t) & 11.9 & 13.1 & 15.2 & 20.1 & 9.4 \\
Share of exitors (t-1, t) & 9.0 & 10.2 & 10.5 & 9.7 & 10.2 \\
\hline
\end{tabular}

Source: Quadros de Pessoal, DEMQE, published by same institution in Demografia das Empresas, 1994.

Note: Values for newborn firms and firms' deaths are estimated values correcting for panel attrition and fluctuation, and mergers. 
